OPEN ACCESS

Edited by:

Francesco Rossi,

University of Campania Luigi Vanvitelli,

Italy

Reviewed by: Joachim Neumann,

Institut für Pharmakologie und

Toxikologie, Germany

Silvana Morello,

University of Salerno, Italy

*Correspondence:

Christopher J. Langmead chris.langmead@monash.edu

Lauren T. May

lauren.may@monash.edu

${ }^{\dagger}$ These authors have contributed equally to this work.

Specialty section: This article was submitted to Cardiovascular and Smooth

Muscle Pharmacology,

a section of the journal

Frontiers in Pharmacology

Received: 10 November 2020 Accepted: 26 January 2021 Published: 11 March 2021

Citation:

Rueda P, Merlin J, Chimenti S,

Feletou M, Paysant J, White PJ,

Christopoulos A, Sexton PM, Summers RJ, Charman WN, May LT and Langmead CJ (2021) Pharmacological Insights Into Safety and Efficacy Determinants for the Development of Adenosine Receptor Biased Agonists in the Treatment of Heart Failure.

Front. Pharmacol. 12:628060. doi: 10.3389/fphar.2021.628060

\section{Pharmacological Insights Into Safety and Efficacy Determinants for the Development of Adenosine Receptor Biased Agonists in the Treatment of Heart Failure}

Patricia Rueda ${ }^{1+}$, Jon Merlin ${ }^{1 \dagger}$, Stefano Chimenti ${ }^{2}$, Michel Feletou ${ }^{2}$, Jerome Paysant ${ }^{2}$, Paul J. White ${ }^{1}$, Arthur Christopoulos ${ }^{1}$, Patrick M. Sexton ${ }^{1}$, Roger J. Summers ${ }^{1}$, William N. Charman ${ }^{1}$, Lauren T. May ${ }^{1 *}$ and Christopher J. Langmead ${ }^{1 *}$

\footnotetext{
${ }^{1}$ Drug Discovery Biology, Monash Institute of Pharmaceutical Sciences, Monash University, Parkville, VIC, Australia,

${ }^{2}$ Cardiovascular Discovery Research Unit, Institut de Recherches Servier, Suresnes, France
}

Adenosine $A_{1}$ receptors $\left(A_{1} R\right)$ are a potential target for cardiac injury treatment due to their cardioprotective/antihypertrophic actions, but drug development has been hampered by on-target side effects such as bradycardia and altered renal hemodynamics. Biased agonism has emerged as an attractive mechanism for $A_{1} R$-mediated cardioprotection that is haemodynamically safe. Here we investigate the pre-clinical pharmacology, efficacy and side-effect profile of the $A_{1} R$ agonist neladenoson, shown to be safe but ineffective in phase Ilb trials for the treatment of heart failure. We compare this agent with the wellcharacterized, pan-adenosine receptor (AR) agonist NECA, capadenoson, and the $A_{1} R$ biased agonist VCP746, previously shown to be safe and cardioprotective in pre-clinical models of heart failure. We show that like VCP746, neladenoson is biased away from $\mathrm{Ca}^{2+}$ influx relative to NECA and the CAMP pathway at the $A_{1} R$, a profile predictive of a lack of adenosine-like side effects. Additionally, neladenoson was also biased away from the MAPK pathway at the $A_{1} R$. In contrast to VCP746, which displays more 'adenosine-like' signaling at the $A_{2 B} R$, neladenoson was a highly selective $A_{1} R$ agonist, with biased, weak agonism at the $A_{2 B} R$. Together these results show that unwanted hemodynamic effects of $A_{1} R$ agonists can be avoided by compounds biased away from $\mathrm{Ca}^{2+}$ influx relative to cAMP, relative to NECA. The failure of neladenoson to reach primary endpoints in clinical trials suggests that $A_{1} R$-mediated $C A M P$ inhibition may be a poor indicator of effectiveness in chronic heart failure. This study provides additional information that can aid future screening and/or design of improved AR agonists that are safe and efficacious in treating heart failure in patients.

Keywords: adenosine A1 receptor agonist, heart failure, G protein-coupled receptor, Biased agonism, neladenoson, capadenoson, VCP-746 


\section{INTRODUCTION}

Heart failure (HF) covers a wide range of clinical and pathophysiological conditions. It is broadly defined as a clinical syndrome whereby the heart fails to supply enough blood to fulfill the metabolic needs of the tissues (Coronel et al., 2001). In general, the pathophysiology of $\mathrm{HF}$ is described by two major categories: 1) HF with reduced ejection fraction (HFrEF), where the left ventricular ejection fraction (LVEF) is <40\%; and 2) HF with preserved ejection fraction $(\mathrm{HFpEF})$ where $\mathrm{LVEF}>50 \%$. A third recently described category of HF with mid-range ejection fraction (HFmEF) is still controversial, but identifies patients with a LVEF of $40-49 \%$ in patients with different underlying characteristics and pathophysiology (Ponikowski et al., 2016). There is a forecast $46 \%$ increase in HF prevalence by 2030 , with over eight million cases in the US alone (Heidenreich et al., 2013; Mozaffarian et al., 2015) illustrating the need for effective treatments.

The most recent guidelines for HFrEF treatment includes angiotensin receptor-neprilysin inhibitors (ARNI) (e.g. sacubitril/valsartan), which reduce the effect of maladaptive neurohormones and block cardiac remodeling (Jessup et al., 2016). Although both basic research and the establishment of clear evidence-based clinical guidelines is improving management of HFrEF, these therapies have adverse hemodynamic effects (Vaduganathan et al., 2015). There is still a need for an approved pharmacological intervention for the treatment of HFpEF (Bonsu et al., 2018) underpinned by an increase in prevalence of this condition (Owan et al., 2006).

To address this, it has been suggested that therapeutic strategies should be aimed at directly attenuating adverse cardiac remodeling whilst being haemodynamically neutral (Vaduganathan et al., 2015). As previously suggested (Greene et al., 2016), fine-tuned modulation of adenosine receptors (ARs), and in particular the $A_{1}$ subtype $\left(A_{1} R\right)$, may provide a route to fulfill these criteria, with the potential to be haemodynamically neutral, improve cardiomyocyte (CM) energetics, cardiac structure and function, and prevent further tissue injury by inducing cardioprotection and reduction of interstitial fibrosis.

Adenosine has been long-known to exert pleiotropic protective and regenerative effects and activates all four adenosine receptor $(A R)$ subtypes $\left(A_{1}, A_{2 A}, A_{2 B}\right.$ and $\left.A_{3} R s\right)$ in different tissues (Linden, 2005). ARs are $G$ protein-coupled receptors (GPCRs) originally classified by their pharmacological response to adenosine, with $A_{1}$ and $A_{3} R$ inhibiting, and $\mathrm{A}_{2 \mathrm{~A}}$ and $\mathrm{A}_{2 \mathrm{~B}} \mathrm{R}$ activating adenylate cyclase (Fredholm et al., 2011). The adenosinergic system impacts major aspects of cardiovascular function, including beat rate, conduction, autonomic control, perfusion, growth and remodeling, and ultimately protection to injury (Headrick et al., 2013). It is well established that all four receptor subtypes are expressed in the cardiovascular system and that their expression levels alter following injury (Cabiati et al., 2014), although full characterization of cell-specific and relative subtype abundance of AR expression is unknown.

In the setting of heart failure, ARs modulate adaptive and maladaptive responses. Cardiomyocyte hypertrophy plays an important role in this process and neurohormonal factors such as catecholamines, angiotensin II or endothelin are involved in cardiac hypertrophy and failure (Frey and Olson, 2003). Inflammation is also a hallmark of cardiac hypertrophy and involves factors such as interleukin (IL)- $1 \beta$ or tumor necrosis factor-alpha (TNF- $\alpha$ ) (Erten et al., 2005; Kuusisto et al., 2012). Importantly, $\mathrm{A}_{1} \mathrm{R}$ agonists reduce both neurohumoral- and inflammation-driven hypertrophy (Liao et al., 2011; Chuo et al., 2016; Puhl et al., 2016).

Cardiac fibroblasts also contribute to the heart failure phenotype, as adverse remodeling by these cells leads to excess generation of extracellular matrix, fibrosis, and causes contractile dysfunction. The $\mathrm{A}_{2 \mathrm{~B}} \mathrm{R}$, which is highly expressed in fibroblasts (Epperson et al., 2009), is the main AR subtype involved in cardiac fibroblast proliferation and collagen synthesis (Dubey et al., 1997; Dubey et al., 1998; Dubey et al., 2001; Chen et al., 2004).

Despite the preclinical efficacy shown by AR agonists, further development of these agents has been compromised by the widespread expression of ARs throughout the body, and their pleiotropic effects on the cardiovascular system. These on-target side effects include modulation of blood pressure, heart rate, atrioventricular $(\mathrm{AV})$ conduction, and renal function. The $A_{1} R$ (highly expressed in the atria) is responsible for changes in heart rate and conduction (Belardinelli et al., 1995; Yang et al., 2007), while the $A_{2 A} R$ and $A_{2 B} R$ subtypes (found in smooth muscle and endothelium) play major roles in vasoregulation (Kemp and Cocks, 1999; Sato et al., 2005). Accordingly, activation of these receptors often leads to changes in blood pressure. Furthermore, $\mathrm{AR}$ activation plays an important role in the hemodynamic balance of the kidney, as $A_{1} R$ mediate cortical vasoconstriction and $\mathrm{A}_{2 \mathrm{~A}} \mathrm{R} / \mathrm{A}_{2 \mathrm{~B}} \mathrm{R}$ mediate medullar vasodilation, thus reducing filtration fraction (Vallon et al., 2008). This is an important consideration where patients with $\mathrm{HF}$ exhibit abnormal cardiorenal hemodynamics that ultimately exacerbate the disease (Damman and Testani, 2015).

In addition to ligands that control the strength of signaling of a GPCR (efficacy), receptors are highly dynamic proteins with different active-state conformations that can be linked to different cellular outcomes. By extension, ligands stabilizing different conformations can specifically promote a subset of signaling or regulatory pathways, a phenomenon known as biased agonism (Kenakin and Christopoulos, 2013). This affords the potential to target GPCRs with improved on-target specificity, as recently established in preclinical models for several GPCR agonists (DeWire et al., 2013; Brust et al., 2015; Baltos et al., 2016; Mallipeddi et al., 2017; Mores et al., 2019). Notably, amongst $\mathrm{A}_{1} \mathrm{R}$ agonists, VCP746 (and derivatives) are biased away from intracellular calcium mobilization relative to other pathways and yield more therapeutically favourable ex vivo pharmacology (Valant et al., 2014; Baltos et al., 2016).

Collectively these data suggest the possibility of identifying adenosine receptor agonists with bias profiles that yield efficacy with high therapeutic index. In 2012 Bayer described capadenoson as a non-ribose, high affinity, highly selective $\mathrm{A}_{1} \mathrm{R}$ agonist with good pharmacokinetics, efficacy, and a promising safety profile. It displayed reduced bradycardia in 
preclinical models and no effects on heart rate at rest in clinical studies (clinical study NCT00568945), while maintaining full cardioprotective potential with amelioration of markers of structural remodeling in preclinical models (Albrecht-Küpper et al., 2012; Sabbah et al., 2013). However, CNS safety and low solubility limited its utility and prompted the development of an improved agent in the form of neladenoson.

Neladenoson (BAY 1067197) is a pro-drug of the pharmacologically active moiety, reportedly a partial $A_{1} R$ agonist, that therefore addresses some of the limitations presented by capadenoson. Neladenoson was cardioprotective in rodents while showing fewer central side effects (Meibom et al., 2017), and was safe and well tolerated in both phase I and phase IIa clinical studies (Voors et al., 2017). Despite this promising preclinical and clinical safety profile, in two phase IIb clinical trials in HFrEF and HFpEF patients (PANTHEON and PANACHE, respectively), neladenoson failed to meet its primary and secondary endpoints for efficacy (Bertero and Maack, 2019; Shah et al., 2019; Voors et al., 2019).

Herein we sought to compare the pre-clinical pharmacology of neladenoson, capadenoson, the tool $\mathrm{A}_{1} \mathrm{R}$ biased agonist VCP746, and the pan-AR agonist, NECA, in molecular signaling assays across adenosine receptors, and in in vivo and ex vivo models of cardio-renal function. Neladenoson displayed high selectivity for the $A_{1} R$, and presented a bias profile similar to VCP746 that is predictive of a lack of overt adenosine-like side effects. However, there was some divergence in other aspects of biased signaling and adenosine receptor subtype activity that might help in the design of future agents that are not only safe, but which have efficacy in treating heart failure in patients.

\section{MATERIALS AND METHODS}

\section{Materials}

Research reagents were obtained from the following suppliers: Dulbeco's modified Eagle medium (DMEM; Life Technologies Australia, 11965118), Hanks' Balanced Salts (Sigma-Aldrich, H2387), trypsin (Life Technologies Australia, 15090046), antibiotic/antimycotic (Life Technologies Australia, 15240062), penicillin/streptomycin (Gibco, 15140-122), FBS (Gibco), Adenosine deaminase (ADA; Sigma-Aldrich, 10102105001), hygromycin B (Scientific INC., H-1012-PBS), Probenecid (Sigma-Aldrich, P8761), Rolipram (Sigma-Aldrich, R6520), Hoechst33342 (ThermoFisher Scientific, H3570), Propidium iodide (Sigma-Aldrich, P4170), 5-Bromo-2'-deoxyuridine (BrdU; Sigma-Aldrich, B5002), 5'-(N-ethylcarboxamido), 5'-Nethylcarboxamidoadenosine (NECA; Sigma-Aldrich, E2387), SLV-320 (Tocris, RDS334410), CGS21680 (Tocris, 1063; Sigma-Aldrich, C141), BAY60-6583 (Tocris, 4472), 2'MeCCPA (Tocris, 2281), MRS1754 (Tocris, 2752), methoxamine (Sigma-Aldrich, M6524), Angiotensin II (AngII; Sigma-Aldrich A9525), interleukin 1beta (IL-1 $\beta$; R\&D systems, 201-LB-005), tumor necrosis factor alpha (TNFa; R\&D systems, 210-TA), Lactate dehydrogenase (LDH) Activity Assay Kit (SigmaAldrich, MAK066), Adenosine Triphosphate (ATP; SigmaAldrich, A26209), Forskolin (Sigma-Aldrich, F3917), Fluo-4
AM (Invitrogen, F14201), Pertussis toxin (PTX; SigmaAldrich, P7208), $\quad\left[{ }^{3} \mathrm{H}\right]$-Leucine (Perkin Elmer, NET135H001MC), [ $\left.{ }^{3} \mathrm{H}\right]$-Proline (Perkin Elmer, NET483001MC), Lance cAMP detection kit (PerkinElmer, AD0262) Alphascreen Surefire ERK1/2 (Thr202/Tyr204) Phosphorylation kit (PerkinElmer, TGRESB), Alphascreen Surefire Akt1/2/3 (p-Ser473) Phosphorylation kit (PerkinElmer, TGRA4S), collagenase Type II (Scimar Australia, LS004176). Neladenoson (as the active metabolite) and capadenoson were synthesized by Servier, and VCP746 was made by SYNthesis Pty. (Melbourne, Australia).

\section{Cell Culture}

Flp-IN CHO- $A_{1} R,-A_{2 A} R,-A_{2 B} R$, and $-A_{3} R$ stable cell lines were generated as previously described (Stewart et al., 2009; Vecchio et al., 2016b), maintained in DMEM supplemented with 10\% FBS and $500 \mu \mathrm{g} / \mathrm{ml}$ hygromycin B and confirmed mycoplasma-free.

\section{cAMP Accumulation}

Cells were trypsinized and seeded in DMEM with 10\% FBS in 96well plates at 20,000 cells/well and incubated overnight. Cells were then washed and incubated in cAMP stimulation buffer ( $140 \mathrm{mM} \mathrm{NaCl}, 5 \mathrm{mM} \mathrm{KCl}, 0.8 \mu \mathrm{M} \mathrm{MgSO}, 0.2 \mathrm{mM} \mathrm{Na}_{2} \mathrm{HPO}_{4}$, $0.44 \mathrm{mM} \mathrm{KH} \mathrm{KH}_{4}, 1.3 \mathrm{mM} \mathrm{CaCl}, 5.6 \mathrm{mM}$ D-glucose, $5 \mathrm{mM}$ HEPES) containing $\mathrm{ADA}(0.1 \mathrm{U} / \mathrm{ml})$, rolipram $(10 \mu \mathrm{M})$ and BSA $(0.1 \%)$ at $37^{\circ} \mathrm{C}$ in a humidified incubator with $5 \% \mathrm{CO}_{2}$ for $1 \mathrm{~h}$. Compounds were then added and incubated for $30 \mathrm{~min}$. When $\mathrm{Ga}_{\mathrm{i}}$-mediated signaling was evaluated, $3 \mu \mathrm{M}$ forskolin was added to the cells $10 \mathrm{~min}$ after compound addition. Stimulation was terminated by removal of buffer and replacement with icecold $100 \%$ ethanol. After ethanol evaporation, cells were lyzed in lysis buffer and cAMP levels were detected using the Lance cAMP kit following manufacturer's instructions. cAMP levels were extrapolated using the standard provided in the kit and then normalized to the forskolin control.

\section{Calcium Mobilization}

Cells were trypsinized and seeded in DMEM with $10 \%$ FBS in 96 well plates at 40,000 cells/well for $8 \mathrm{~h}$ at $37{ }^{\circ} \mathrm{C}$ in a humidified incubator with $5 \% \mathrm{CO}_{2}$. Cells were then incubated in serum-free medium overnight, washed and incubated in calcium stimulation buffer $\left(146 \mathrm{mM} \mathrm{NaCl}, 5 \mathrm{mM} \mathrm{KCl}, 1 \mathrm{mM} \mathrm{MgSO}_{4}, 1.3 \mathrm{mM} \mathrm{CaCl}_{2}\right.$, and $1.5 \mathrm{mM} \mathrm{NaHCO}, 10 \mathrm{mM}$ D-glucose, $10 \mathrm{mM} \mathrm{HEPES}$ ) containing ADA $(0.1 \mathrm{U} / \mathrm{ml})$, probenecid $(2.5 \mathrm{mM})$, BSA $(0.5 \%)$ and Fluo-4 AM $(1 \mu \mathrm{M})$ for $1 \mathrm{~h}$. Fluorescence was detected on a FlexStation plate reader (molecular Devices; Sunnyvale, CA, USA) after the automated addition of buffer in the absence or presence of receptor ligands. Data were analyzed as the difference between the peak and baseline reads and normalized to the ATP $(100 \mu \mathrm{M})$ response.

\section{ERK1/2 and Akt1/2/3 Phosphorylation}

Cells were trypsinized and seeded in DMEM with 10\% FBS in 96well plates at 40,000 cells/well for $8 \mathrm{~h}$ at $37^{\circ} \mathrm{C}$ in a humidified incubator with $5 \% \mathrm{CO}_{2}$. Cells were then incubated in serum-free medium overnight, and ADA $(0.1 \mathrm{U} / \mathrm{ml})$ added $1 \mathrm{~h}$ prior to assay. Cells were then exposed to DMEM in the absence or presence of 
receptor ligands and agonist concentration-response curves were generated at the time of peak response. Stimulation was terminated by rapid removal of media and addition of $50 \mu \mathrm{L} /$ well or AlphaScreen SureFire kit lysis buffer. Detection of either ERK1/2 or Akt1/2/3 phosphorylation was performed as described in the corresponding AlphaScreen SureFire kits and fluorescence measured with an EnVision plate reader (PerkinElmer, Boston, MA). Data were normalized to the response elicited upon stimulation of cells with $10 \%$ FBS.

\section{Cell Survival}

Cells were trypsinized and seeded in DMEM 10\% plus FBS in 96well plates at 40,000 cells/well for $8 \mathrm{~h}$ at $37{ }^{\circ} \mathrm{C}$ in a humidified incubator with $5 \% \mathrm{CO}_{2}$. After $8 \mathrm{~h}$, plates were rinsed in serumfree DMEM and then incubated in serum-free medium overnight. Media was then changed to fresh, sterile calcium stimulation buffer, containing ADA $(0.1 \mathrm{U} / \mathrm{mL})$ and pen/strep $(1 \mathrm{U} / \mathrm{mL})$ and incubated for a further $24 \mathrm{~h}$. Hoechst33342 $(200 \mu \mathrm{M}$; to define all cells) and propidium iodide (PI; $50 \mu \mathrm{g} / \mathrm{ml}$; to define dead/dying cells) were added to two wells, incubated at $37^{\circ} \mathrm{C}$ for $30 \mathrm{~min}$, and cell nuclei counts detected using the Operetta (PerkinElmer, Boston, MA) using manufacturer's protocols. This defined $0 \%$ cell death for subsequent assay. Varying concentrations of adenosine receptor agonists were added to the remaining wells and cells incubated at $37^{\circ} \mathrm{C}$ for $24 \mathrm{~h}$. Finally, Hoechst 33342 and PI stains were added to all wells, incubated for $30 \mathrm{~min}$, and nuclei counts detected on the Operetta. Immediately prior to addition of stains, buffer was removed from two wells and MilliQ water added to lyse cells as a positive control. Data are expressed as a percentage of surviving cells.

\section{Cardiomyocyte Isolation and Culture}

Neonatal cardiac myocytes (CM) were isolated from 1 to 2 dayold Sprague-Dawley rat pups using enzymatic digestion. Briefly, animals were euthanized and the hearts isolated by thoracic incision and kept in Hanks solution. Then ventricles were isolated and incised at the apex to increase tissue surface exposure. Tissue was then incubated overnight at $4^{\circ} \mathrm{C}$ with trypsin. After trypsin deactivation with fresh FBSsupplemented DMEM, tissue was further digested by four cycles of collagenase incubation. Cells were then recovered by centrifugation and seeded in DMEM supplemented with FBS on gelatin-coated dishes for $2 \mathrm{~h}$ in order to select against adherent fibroblasts. The remaining floating cardiomyocytes where then collected, counted, and seeded in either 12-well plates at a density of 300,000 cells/well, or 96-well "chimney well" cell culture plates (Eppendorf) at a density of 37,500 cells/well. Cells were maintained in DMEM supplemented with 10\% FBS and BrdU $(100 \mu \mathrm{M})$ was included for the first three days of culture.

\section{$\left[{ }^{3} \mathrm{H}\right]$-Leucine Incorporation in Cardiomyocytes}

To measure hypertrophy by $\left[{ }^{3} \mathrm{H}\right]$-leucine incorporation, after five days in culture cardiomyocytes were starved overnight in serumfree DMEM and then pre-treated with adenosine receptor agonists or vehicle for $2 \mathrm{~h}$ before hypertrophic stimuli [IL-1 $\beta$
(10 ng/ml), TNF- $\alpha(10 \mathrm{ng} / \mathrm{ml})$, or Ang II (100 nM)], after which $1 \mu \mathrm{Ci}$ of $\left[{ }^{3} \mathrm{H}\right]$-leucine was added to each well. Cells were incubated at $37^{\circ} \mathrm{C}$ with $5 \% \mathrm{CO}_{2}$ in a humidified incubator for $72 \mathrm{~h}$, washed with $\mathrm{PBS}$ and lyzed using $0.2 \mathrm{M} \mathrm{NaOH}$. After adding UltimaGold scintilliant to the samples, radioactivity was detected using a MicroBeta2 Plate Counter (PerkinElmer Life Sciences). Data were normalized to the signal obtained for the vehicle treated samples.

\section{$\left[{ }^{3} \mathrm{H}\right]-$ Proline Incorporation in Cardiac Fibroblasts}

Cardiac fibroblasts were recovered from gelatin-coated dishes described above through trypsination and plated in 12-well plates at a density of 50,000 cells/well for $\left[{ }^{3} \mathrm{H}\right]$-proline incorporation assays in high glucose DMEM supplemented with $10 \%$ FBS. After 4 days cardiac fibroblasts were serum starved in DMEM overnight and then treated with vehicle, VCP746 or neladenoson $2 \mathrm{~h}$ prior to fibrotic stimuli TGF $\beta(10 \mathrm{ng} / \mathrm{ml})$ or AngII $(10 \mathrm{nM}) .\left[{ }^{3} \mathrm{H}\right]$-Proline $(1 \mu \mathrm{Ci} /$ well $)$ was then added to each well. After $72 \mathrm{~h}$ cells were washed, lyzed and radioactivity detected as per $\left[{ }^{3} \mathrm{H}\right]$-leucine assay, described above.

\section{Cardiomyocyte Lactate dehydrogenase Release and PI Staining}

To determine apoptotic effects of adenosine receptor agonists, a combined LDH release and PI stain assay was performed with an identical treatment regimen to $\left[{ }^{3} \mathrm{H}\right]$-leucine incorporation assays: $2 \mathrm{~h}$ pre-treatment with adenosine receptor agonists before stimulation with IL- $1 \beta(10 \mathrm{ng} / \mathrm{ml})$, TNF- $\alpha(10 \mathrm{ng} / \mathrm{ml})$ or Ang II ( $100 \mathrm{nM})$ for $72 \mathrm{~h}$ at $37^{\circ} \mathrm{C}$ with $5 \% \mathrm{CO}_{2}$ in a humidified incubator. On the day of assay, $20 \mu \mathrm{L}$ of extracellular media from cardiomyocyte plates was transferred to a new 96-well plate, with NADH standard dilutions, and a colorimetric LDH release assay performed as per manufacturer's instructions (Sigma-Aldrich; cat no: MAK066). Absorbance (450 nm) was detected at $3 \mathrm{~min}$ intervals (FlexStation) until it reached the upper range of standards. Data ("cell viability") are expressed as a percentage of control-treated wells. In parallel, the cells without washing were treated with DMEM containing Hoescht33342 $(200 \mu \mathrm{M})$ and PI $(50 \mu \mathrm{g} / \mathrm{ml})$ for $1 \mathrm{~h}$ at $37^{\circ} \mathrm{C}$. Hoechst33342-and PI-positive nuclei were quantified on the Operetta using manufacturer's protocol. Data ("cell survival") are a ratio of $\mathrm{PI} / \mathrm{Hoechst} 33342$ counts, expressed as a percentage of control-treated wells.

\section{Measurement of Beat Rate in Cardiomyocytes}

Rat cardiomyocytes were cultured 4 days in 96-well plates before cells were checked visually to have widespread cell-cell contact and uniform beating across the well. Media was then changed to fresh DMEM with $10 \%$ FBS $24 \mathrm{~h}$ prior to assay, and $0.1 \mathrm{U} / \mathrm{mL}$ ADA added $2 \mathrm{~h}$ prior to assay. For assay, spontaneous contractions were brightfield recorded (Nikon Ti-E microscope; $37^{\circ} \mathrm{C}, 5 \% \mathrm{CO}_{2}$ ) for 100 frames at 10 frames/sec to define a basal beat rate. Cells were then incubated with ligand for 
$5 \mathrm{~min}$ and recorded again. Quantification of contractions was determined by time-resolved analysis (Image J 1.51n) of peak intensity of several representative cardiomyocytes within the field of view. All data are expressed as $\%$ of beat rate prior to addition for each replicate. Where SLV320 $(1 \mu \mathrm{M})$ was used, it was added $15 \mathrm{~min}$ prior to basal recording.

\section{Measurement of Beat Rate in Isolated Rat Atria}

Experiments were carried out on male Wistar rats (400-450 g) from JANVIER Labs (Center d'Elevage René JANVIER, Le Genest Saint-Isle, France). Rats were anesthetized with sodium pentobarbital $(54.7 \mathrm{mg} / \mathrm{kg}$ intraperitoneal). Right atria were carefully removed and immediately immersed in physiological salt solution (PSS) at $4^{\circ} \mathrm{C}$ containing (in $\mathrm{mM}$ ): $\mathrm{NaCl} \mathrm{112,} \mathrm{KCl} 5$, $\mathrm{KH}_{2} \mathrm{PO}_{4} 1, \mathrm{MgSO}_{4} 1.2, \mathrm{CaCl}_{2} 2.5, \mathrm{NaHCO}_{3}$ 29.8, glucose 11.5, EDTA 0.02, pH $7.4 \pm 0.05$. Preparations were suspended vertically in an organ bath filled with $20 \mathrm{ml}$ of PSS maintained at $35^{\circ} \mathrm{C}$ and gassed with a mixture of $95 \% \mathrm{O}_{2}+5 \% \mathrm{CO}_{2}$. Isometric tension was recorded by means of a force transducer (EMKA Technologies, Paris, France). Atria were stretched to obtain a resting tension of $0.2-1 \mathrm{~g}$. Right atria spontaneous beating frequency was measured using specific software (IOX EMKA Technologies, Paris, France). Only preparations with a basal beating rate between 200 and 300 beats per minute (bpm) were included.

After a 30 min equilibration period, dose-response curves were generated with cumulative concentrations $\left(10^{-9} \mathrm{M}\right.$ to $\left.10^{-5} \mathrm{M}\right)$ of NECA, CGS21680, BAY60-6583 or $2^{\prime} \mathrm{MeCCPA}$ every $30 \mathrm{~min}$. Due to their long kinetic of effect, VCP746 and neladenoson were tested with a single concentration $\left(10^{-7} \mathrm{M}\right.$ to $\left.10^{-5} \mathrm{M}\right)$ per preparation, beating rate was measured at $120 \mathrm{~min}$ after each concentration. To assess NECA specificity, atria were pre-treated (30 min) with the specific A1R antagonist SLV320 at $10 \mathrm{nM}$ or $100 \mathrm{nM}$. Then, two successive concentrations of NECA (10 and $100 \mathrm{nM})$ were added for $1 \mathrm{~h}$.

Spontaneous beating frequency of right atria, measured at fixed time or concentration, was expressed in bpm. The effects of the compounds were expressed as percent changes from the basal atrial beating frequency.

\section{Measurement of Heart Rate in Moving, Conscious Animals}

Male Wistar rats ( 8 weeks old, $\mathrm{n}=4-7$ ) were implanted with a radio telemetric device equipped with a pressure transducer (HDS10, Data Sciences International) under anesthesia with isoflurane (2\%, VETFLURANE ${ }^{\circledR}$, VIRBAC, France). Rats received buprenorphine $\left(50 \mu \mathrm{g} / \mathrm{kg}\right.$ s. c., BUPRECARE ${ }^{\circledR}$, Axience SAS, France) for analgesia prior to surgery. After laparotomy the telemetric device catheter was inserted into the abdominal aorta and secured with cellulose patch and tissue adhesive $\left(3 \mathrm{M}, \mathrm{VETBOND}^{\mathrm{TM}}\right)$ around the insertion point. The body of the device was placed in the abdominal cavity and sutured to the inner side of the abdominal musculature then the skin plan was closed.
After a recovery period of two weeks a catheter (polyethylene/ silastic) was introduced in jugular vein for drug administration by infusion. Briefly, the jugular vein was dissected and a small incision was made in order to introduce the catheter into the vessel. The catheter was tunneled subcutaneously to the dorsum of the neck and drawn back up through the skin. Rats were kept on a heating pad $\left(38^{\circ} \mathrm{C}\right)$ until fully recovered from anesthesia. Animals were allowed 2-3 days recovery before being used for the experiment. On the day of study, $20 \mathrm{~min}$ infusion protocols were performed at different doses of test compounds to achieve predetermined plasma drug concentrations. Acquisition of heart rate was done with IOX (EMKA, France), sampled and averaged over $5 \mathrm{~s}$ every $5 \mathrm{~s}$. The mean of the values recorded for each dose was calculated using the software Data Analyst (EMKA, France).

\section{Vasorelaxation of Rat Thoracic Aorta}

Experiments were carried out on male Wistar rats (400-450 g) from JANVIER Labs (Center d'Elevage René JANVIER, Le Genest Saint-Isle, France). Rats were anesthetized with sodium pentobarbital $(54.7 \mathrm{mg} / \mathrm{kg}$ intraperitoneal). The thoracic aorta was quickly removed placed in ice-cold physiological salt solution (PSS) at $4^{\circ} \mathrm{C}$ containing (in $\mathrm{mM}$ ): $\mathrm{NaCl} 112, \mathrm{KCl} 5, \mathrm{KH}_{2} \mathrm{PO}_{4} 1$, $\mathrm{MgSO}_{4}$ 1.2, $\mathrm{CaCl}_{2} 2.5, \mathrm{NaHCO}_{3} 29.8$, glucose 11.5, EDTA 0.02, $\mathrm{pH} 7.4 \pm 0.05$. Then the aorta was cleaned of adhering fat and connective tissue and cut transversely into 3-4 mm rings denuded or not of endothelium and placed in $20 \mathrm{ml}$ organ baths containing PSS maintained at $37^{\circ} \mathrm{C}$ with continuous bubbling of $95 \% \mathrm{O}_{2}+5 \% \mathrm{CO}_{2}$. Aortic rings were mounted vertically between two stainless wire hooks and then suspended. For isometric force response measurement, the changes in tension of pre-contracted intact or denuded rings were continuously monitored and recorded using specific software (IOX EMKA Technologies, Paris, France). Aortic rings were equilibrated for $60 \mathrm{~min}$ with a resting force of $2.5 \mathrm{~g}$.

Aortic rings were constricted with phenylephrine $(1 \mu \mathrm{M})$ to obtain a steady contraction then relaxed with cumulative acetylcholine concentration $(0.01-10 \mu \mathrm{M})$ to check the integrity of the endothelium. The absence of endothelium was confirmed by the lack of responsiveness to acetylcholine. Aortic rings were washed several times with PSS and equilibrated for $30 \mathrm{~min}$. Then the rings were constricted with phenylephrine $(1 \mu \mathrm{M})$ to obtain a steady contraction and the agonists were added in cumulated concentrations $(1 \mathrm{nM}-10 \mu \mathrm{M})$ to the organ bath. At the end of each experiment, the rings were tested for viability by being maximally dilated with $100 \mu \mathrm{M}$ papaverine. Relaxation was expressed as a percent of maximal relaxation to papaverine and as percent changes from phenylephrine contraction.

\section{Renal Vasodilation and Vasoconstriction}

Male Wistar rats (300-400 g), purchased from Janvier Labs (Center d'Elevage René Janvier, Le Genest Saint-Isle, France) were anesthetized intraperitoneal with a mixture of ketamine $(110 \mathrm{mg} / \mathrm{kg})$ and xylazine $(7.5 \mathrm{mg} / \mathrm{kg})$. The left kidney was exposed by midline ventral laparotomy and the left renal artery was cannulated. The kidney was then perfused at 
constant flow via a peristaltic pump with warmed $\left(37^{\circ} \mathrm{C}\right)$ and oxygenated $\left(95 \% \mathrm{O}_{2}-5 \% \mathrm{CO}_{2}\right)$ Tyrode solution of the following composition (mM): $\mathrm{NaCl} \mathrm{137;} \mathrm{KCl} 2.7 ; \mathrm{CaCl}_{2}$ 1.8; $\mathrm{MgCl}_{2} 1.1$; $\mathrm{NaHCO}_{3}$ 12.0; $\mathrm{NaHPO}_{4}$ 0.42; calcium disodium EDTA 0.026 and glucose 5.6. The perfused kidney was removed from the surrounding fat and placed in a perfusion chamber. The change in renal vascular resistance was recorded as changes in renal perfusion pressure (RPP) measured downstream of the pump via a pressure transducer (P10EZ, Statham, France) connected to a data acquisition system (IOX2, EMKA Technologies, France). Pharmacological agents were administered either via an infusion pump placed upstream to the perfusion pump (concentrations expressed below in $\mathrm{mol} / \mathrm{L}$ ) or injected as a bolus of $20 \mu \mathrm{L}$ (doses expressed in mol) into the perfusion circuit.

In order to study renal vasodilator response, a sustained and stable vasoconstriction was maintained by permanent infusion of methoxamine $(10 \mu \mathrm{mol} / \mathrm{L})$. After stable vasoconstriction, doseresponse curves were performed by using BAY60-6583 (1 $\rho$ mol to $10 \mathrm{nmol})$, neladenoson ( $10 \rho \mathrm{mol}$ to $30 \mathrm{nmol})$, or VCP746 (1 $\rho \mathrm{mol}$ to $10 \mathrm{nmol})$. To verify the effect of BAY60-6583 in the renovascular responses to vasodilation, selective A2A (SCH $442416100 \mathrm{nM}$ ) or A2B (MRS $1754100 \mathrm{nM}$ ) receptor antagonists were administered by perfusion to the kidney $30 \mathrm{~min}$ before the agonist. Vasodilation was expressed by the negative delta between the response and Methoxamine constriction.

In order to measure renal vasoconstriction, methoxaminetreated $(0.01 \mu \mathrm{mol} / \mathrm{L})$ kidneys were stimulated with $0.1 \mu \mathrm{mol} / \mathrm{L}$ forskolin. Under these conditions, purine inhibition of adenylate cyclase would blunt the forskolin effect thereby producing vasoconstriction (Kenakin and Pike, 1987). Then $2^{\prime}$ MeCCPA ( $1 \rho \mathrm{mol}$ to $10 \mathrm{nmol})$, NECA ( $1 \rho \mathrm{\rho mol}$ to $100 \mathrm{nmol})$, neladenoson $(1 \rho \mathrm{mol}$ to $30 \mathrm{nmol})$ or VCP746 $(1 \rho \mathrm{mol}$ to $10 \mathrm{nmol})$ were administered by bolus injection to induce vasoconstriction. Before methoxamine and forskolin infusion two bolus injections of noradrenaline (NA, $0.3 \mathrm{nmol}$ ) were performed to obtain reference vasoconstriction. To verify $2^{\prime} \mathrm{MeCCPA}$ effect on renovascular response, a selective $\mathrm{A} 1$ receptors antagonist (SLV320 0.1 and $0.01 \mu \mathrm{M}$ ), was administered $30 \mathrm{~min}$ prior agonist administration. Vasoconstriction was expressed as difference between the response and Methoxamine/Forskolin induced constriction, or as the \% of NA constriction for the experiment with $2^{\prime}$ MECCPA.

\section{Statistics}

All data are expressed as mean \pm SEM or mean \pm SD (as indicated) of $n$ experiments. For concentration response data, curves were analyzed using three-parameter nonlinear curve fitting (GraphPad Prism 8.02) of grouped data. $\mathrm{pK}_{\mathrm{b}}$ values of VCP746 at $\mathrm{hA}_{3}$ receptor were determined using the Schild method (Arunlakshana and Schild, 1959) and calculated using the operational model plus agonism (GraphPad Prism 8.02). Statistical analysis was performed using paired Student's t-test, repeated measures one-way analysis of variance (ANOVA) or two-way ANOVA with Dunnett's post-hoc test, as indicated in results. $p<0.05$ was considered significant.
Ligand bias at adenosine receptors was analyzed using methods described previously (Kenakin and Christopoulos, 2013; Van Der Westhuizen et al., 2014). Cyclic AMP accumulation, calcium mobilization and protein phosphorylation assays were performed using all four $A R$ agonists in parallel, allowing calculation of $\log \left(\tau / \mathrm{K}_{\mathrm{A}}\right)$ values for each individual $n$, and subsequent calculation of bias to include weighted mean \pm SEM of $n$. Bias $\left(\log \left(\tau / \mathrm{K}_{\mathrm{A}}\right), \Delta \log (\tau /\right.$ $\left.\left.\mathrm{K}_{\mathrm{A}}\right), \Delta \Delta \log \left(\tau / \mathrm{K}_{\mathrm{A}}\right)\right)$ was calculated in Microsoft Excel (2010) and bias plots generated using the radar plot feature. Analysis of $\Delta \log \left(\tau / \mathrm{K}_{\mathrm{A}}\right)$ and $\Delta \Delta \log \left(\tau / \mathrm{K}_{\mathrm{A}}\right)$ were performed using multiple two-way ANOVA with multiple comparisons (GraphPad Prism 8.02).

\section{Study Approval}

Animal experiments were conducted in accordance to either Servier Ethical committee guidelines or the Monash Institute of Pharmaceutical Sciences animal ethics committee-approved protocols (ethics approval number: MIPS.2017.18) and conformed to the requirements of the National Health and Medical Research Council of Australia Code of practice for the care and use of animals for scientific purposes.

\section{RESULTS}

\section{Neladenoson and Capadenoson Are Differentially Biased at the Adenosine A1 Receptor Compared With VCP746}

In stably-transfected $\mathrm{CHO}-\mathrm{A}_{1} \mathrm{R}$ cells, VCP746, neladenoson, and capadenoson were all partial agonists for calcium mobilization relative to the prototypical full agonist NECA (Figure 1A), yet displayed full agonism for inhibition of cAMP accumulation (Figure 1B). The calcium response was sensitive to pretreatment with pertussis toxin (data not shown), suggesting that, like cAMP inhibition and ERK1/2 phosphorylation (Germack and Dickenson, 2004), it is downstream of canonical $\mathrm{Ga}_{\mathrm{i} / \mathrm{o}}$-coupling. Analysis of bias, using NECA as a reference agonist and cAMP inhibition as the reference pathway, demonstrated that the synthetic ligands were biased away from calcium mobilization relative to cAMP (Figure 1C), a property that is reported to be predictive of a lower propensity for bradycardia.

However, neladenoson and capadenoson differed from the VCP746 profile for cell survival (1D), and phosphorylation of ERK1/2 (Figure 1E) and Akt1/2/3 (Figure 1F; Supplementary Table S1), being biased away from these endpoints compared with NECA and VCP746 (Figure 1C; Supplementary Figure S1). Interestingly, despite the structural similarity of the two investigational agents, neladenoson consistently displayed lower potency than capadenoson across all assays, particularly for protein phosphorylation (Figures 1E,F). Neladenoson, like VCP746, is biased away from $\mathrm{Ca}^{2+}$ influx relative to the cAMP pathway, a profile linked to reduced adenosine-like side effects. However, unlike VCP746, neladenoson shows additional bias away from the MAPK pathway. 

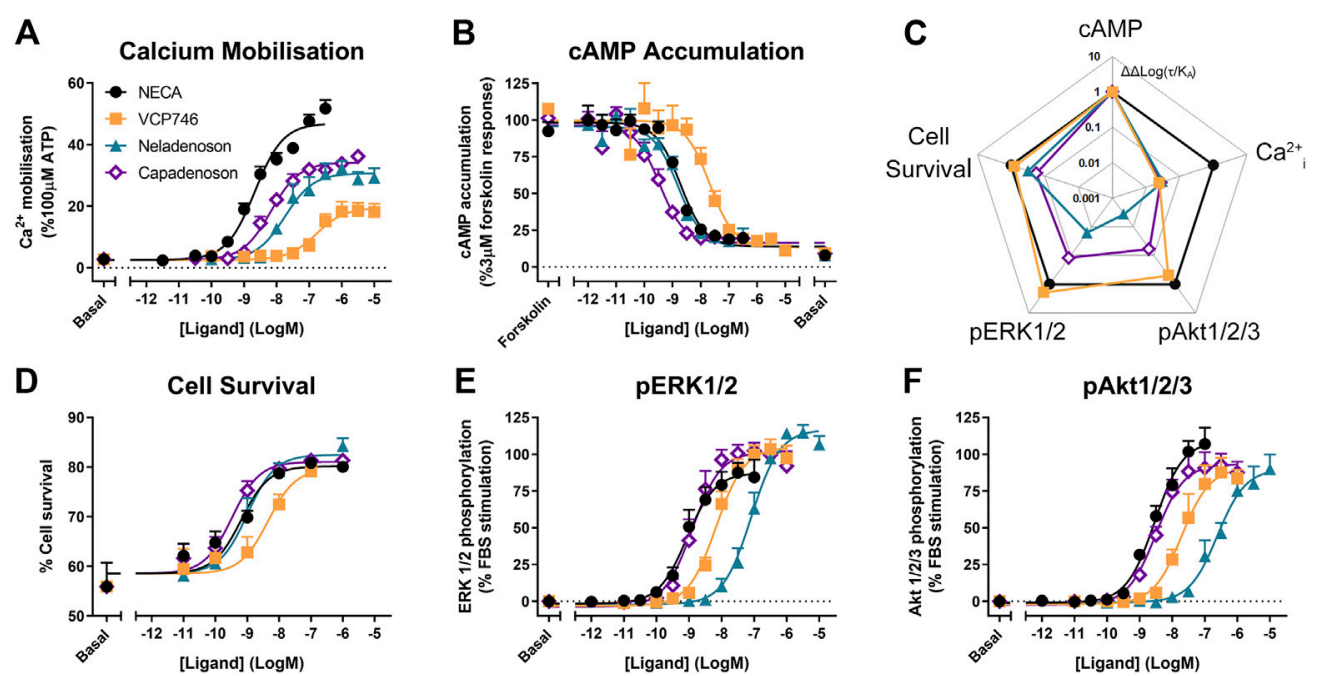

FIGURE 1 | Multi-pathway profiling at the $\mathrm{A}_{1} \mathrm{R}$. Adenosine receptor agonists were analyzed in $\mathrm{CHO}-\mathrm{h} \mathrm{A}_{1} \mathrm{R}$ cells in assays of calcium mobilization $(\mathbf{A} ; \mathrm{n}=4)$, inhibition of cAMP accumulation (B; $n=6)$, cell survival $(\mathbf{D} ; n=3)$ or phosphorylation of ERK1/2 $(\mathbf{E} ; n=5)$ and Akt1/2/3 (F; $n=3)$. These data were used to calculate bias, where $\log \left(\tau / \mathrm{K}_{A}\right)$ are normalized to NECA $\left(\Delta \log \left(\tau / \mathrm{K}_{A}\right)\right)$ and CAMP accumulation $\left(\Delta \Delta \log \left(\tau / \mathrm{K}_{\mathrm{A}}\right)\right.$; C). Statistical significance of bias is reported in Supplementary Figure S1. Concentration response data are expressed as mean \pm SEM.

\section{Functional Adenosine Receptor Subtype Selectivity and Differential Biased Agonism at the Adenosine $A_{2 B}$ Receptor}

As all adenosine receptor subtypes potentially contribute to the in vivo activity of $\mathrm{AR}$ agonists, the ligands were evaluated in $\mathrm{CHO}$ cells stably expressing the $A_{2 A} R, A_{2 B} R$ or $A_{3} R$ subtypes. Compared with the reference agonist NECA, VCP746 had high potency at the $\mathrm{A}_{2 \mathrm{~B}} \mathrm{R}$ and weak activity at the $\mathrm{A}_{2 \mathrm{~A}} \mathrm{R}$ and little or no activity at the $A_{3} R$ (Figure 2; Supplementary Figure S2; Supplementary Tables S2-S4). Capadenoson stimulated other AR subtypes with an order of selectivity of $A_{1}>A_{2 B}>$ $A_{2 A}>A_{3}$. In contrast, neladenoson had no measurable activity at the $A_{2 A} R$ or $A_{3} R$, but activated the $A_{2 B} R$ as a partial, biased agonist except for cAMP inhibition where it was a low potency full agonist (Figure 2; Supplementary Tables S2-S4).

The signaling profile of neladenoson, capadenoson, and VCP746 at the $A_{2 B} R$ revealed marked differences (Figure 2). In contrast to the $A_{1} R, V C P 746$ was a non-biased full agonist at the $A_{2 B} R$, with NECA-like activity for inhibition of cAMP accumulation, calcium mobilization, ERK1/2, and Akt1/2/3 phosphorylation. On the other hand, despite being a full agonist for cAMP accumulation at the $\mathrm{A}_{2 \mathrm{~B}} \mathrm{R}$, capadenoson was a weak, partial agonist, biased away from calcium mobilization, ERK1/2, and Akt1/2/3 phosphorylation relative to NECA. As with the $A_{1} R$, neladenoson was less potent than capadenoson at the $\mathrm{A}_{2 \mathrm{~B}} \mathrm{R}$ subtype, showing bias away from ERK1/2 and Akt1/2/3 phosphorylation relative to NECA, and had no detectable activity on calcium mobilization (Figure 2; Supplementary Table S3; Supplementary Figure S1).

Agonist activity at the $\mathrm{A}_{2 \mathrm{~A}} \mathrm{R}$ was also different for neladenoson. In contrast to capadenoson and VCP746, which were weak, partial, nonbiased agonists, neladenoson did not activate the $\mathrm{A}_{2 \mathrm{~A}} \mathrm{R}$ subtype
(Figure 2; Supplementary Table S2). Of the test agents, only VCP746 showed agonist activity at the $\mathrm{A}_{3} \mathrm{R}$ (in pERK1/2; Figure 2), and was a low affinity antagonist for $\mathrm{A}_{3} \mathrm{R}$-stimulated calcium mobilization and pERK1/2 (Supplementary Figure S2). Taken together, the pharmacological characterization of these compounds at adenosine receptor subtypes shows that neladenoson is a selective $A_{1} R$ biased agonist, with biased, weak agonism at the $A_{2 B} R$ subtype, while VCP746 is a biased $A_{1} R$ agonist and potent unbiased agonist at $\mathrm{A}_{2 \mathrm{~B}} \mathrm{R}$.

In order to broadly assess the physiological and pathophysiological effects of VCP746 and neladenoson in heart failure, these compounds were examined in a range of ex vivo and in vivo models to study beat/ heart rate, hypertrophy/remodeling, aortic vasorelaxation, and renal vasoconstriction and vasorelaxation (Figure 3).

\section{VCP746 and Neladenoson Are Anti-hypertrophic in Cardiomyocytes}

Putative anti-remodelling effects were assessed by $\left[{ }^{3} \mathrm{H}\right]$-leucine incorporation in cardiac myocytes as a marker of hypertrophy and remodeling associated with chronic heart failure. The antihypertrophic effect of adenosinergic agonists, including VCP746, is believed to be mediated by $A_{1} R$ (Liao et al., 2011; Chuo et al., 2016). In the current study TNFa, IL1 $\beta$, or Ang II induced neonatal ventricular cardiomyocyte (NVCM) hypertrophy that was prevented by pre-treatment with VCP746 or neladenoson in a concentration-dependent manner (Figure 4). These effects occurred over the same range of concentrations for both drugs, despite the 10 -fold higher potency of neladenoson for $A_{1} R$ mediated cAMP inhibition (Figure 1). None of the compounds showed a significant effect on NVCM viability as measured by both PI staining or LDH release assays (Supplementary Figure S3), indicating that the inhibitory effects are not due to a reduction on cell viability. 

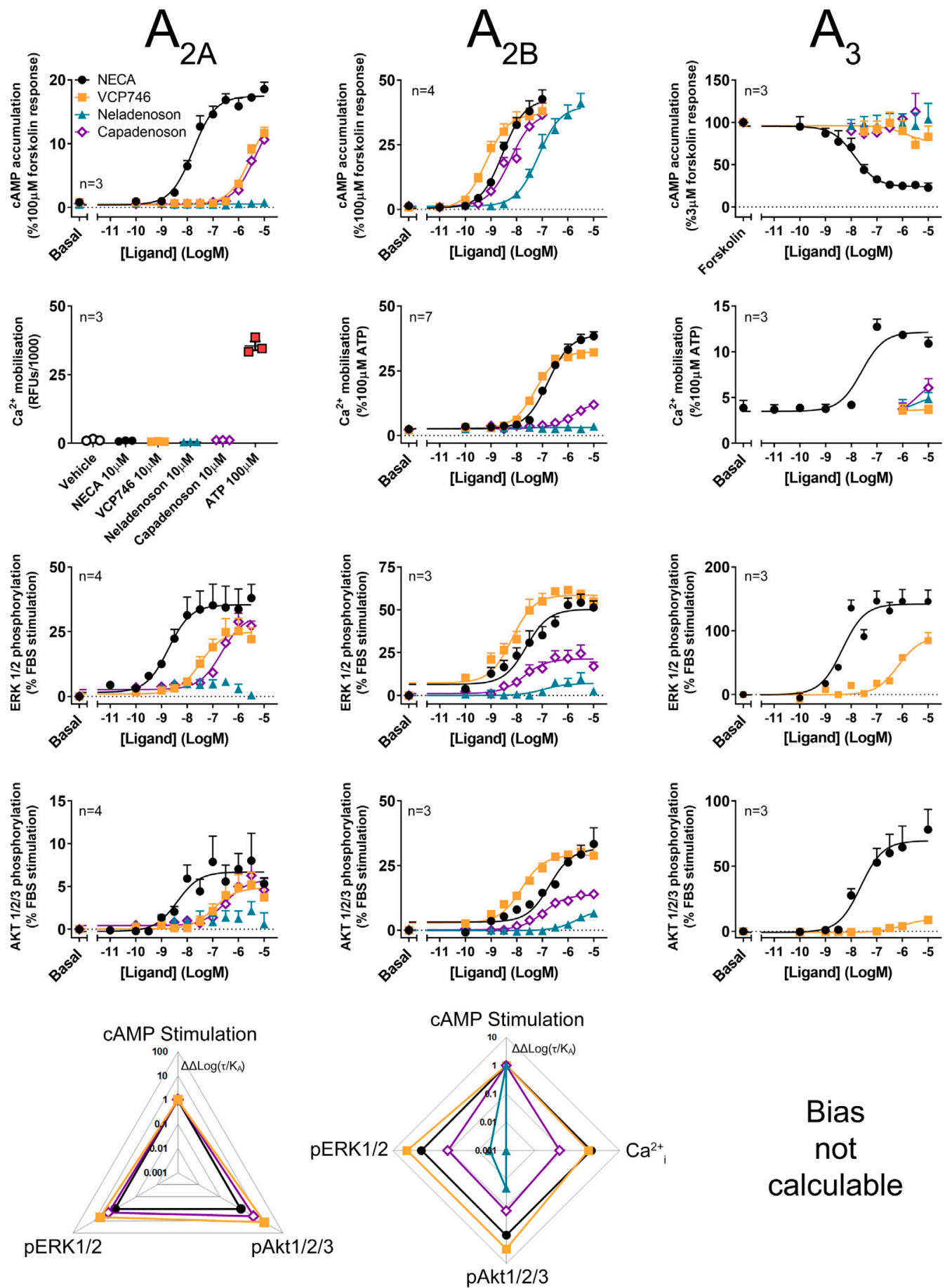

FIGURE 2 | Multi-pathway profiling at the $A_{2 A} R, A_{2 B} R$ and $A_{3} R$. Adenosine receptor agonism was analyzed in $C H O-h A_{2 A} R$ (left panels), $C H O-h A_{2 B} R$ (center panels) and $\mathrm{CHO}-h \mathrm{~A}_{3} \mathrm{R}$ cells (right panels). Cells were analyzed in cAMP (top row), calcium (second row), and phosphorylation of ERK $1 / 2$ (third row) and $A k t 1 / 2 / 3$ (fourth row), with calculated bias shown in the lower row. As bias data are normalized to NECA and the CAMP pathway, where there is no response to NECA at a pathway, ligand-induced cAMP in a cell line, bias cannot be calculated. Statistical analyses of bias are shown in Supplementary Figure S1. Concentration response data are expressed as mean \pm SEM. 


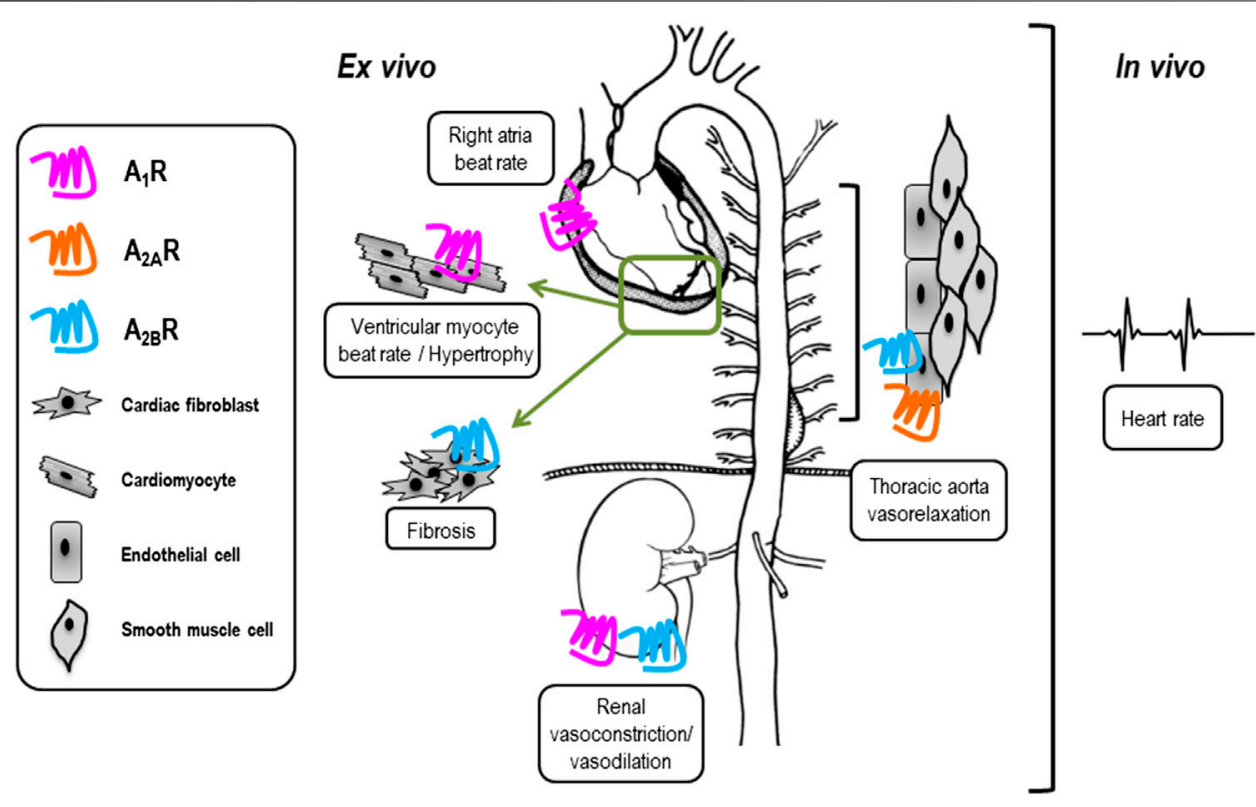

FIGURE 3 | Tissue-specific expression of adenosine receptors may influence side-effect profile of compounds used in vivo. VCP746 and neladenoson were studied further in the indicated ex vivo and in vivo assays (boxed) to determine expected side-effect profiles. Known sites of primary functional adenosine receptor expression are indicated by blue $\left(A_{1} R\right)$, orange $\left(A_{2 A} R\right)$ and pink $\left(A_{2 B} R\right)$ receptors.

\section{Both VCP746 and Neladenoson Have Anti-fibrotic Effects in Cardiac Fibroblasts}

In cardiac fibroblasts, Ang II and tumor growth factor-beta (TGF $\beta$ ) significantly increased $\left[{ }^{3} \mathrm{H}\right]$-proline incorporation, a marker of fibrosis (Figure 5). Pre-treatment with either VCP746 or neladenoson (300 nM) reduced the effect of Ang II by $40 \%$ (Figure 5A), putatively by activation of adenosine $A_{2 B}$ receptors (Vecchio et al., 2016a), although neither agent affected $\left[{ }^{3} \mathrm{H}\right]$-proline incorporation driven by TGF $\beta$ (Figure 5B). These effects are consistent with the signaling profile of the agonists at the $A_{2 B} R$ since both are able to activate this receptor.

\section{VCP746 and Neladenoson Display Limited and Differential Effects on Beat/Heart Rate In Vitro and In Vivo}

One of the major barriers to the use of adenosine $A_{1} R$ agonists in the clinic is $\mathrm{A}_{1} \mathrm{R}$-mediated negative chronotropy i.e. bradycardia. To evaluate the relative propensity to modulate beat rate, we compared VCP746 and neladenoson head-to-head in primary NVCMs, rat atria ex vivo, and in conscious rats by telemetry.

In primary rat NVCMs, neladenoson (30 and $300 \mathrm{nM}$ ) produced a small, but significant reduction in spontaneous beat rate (Figure 6A), whereas VCP746 $(300 \mathrm{nM})$ was without significant effect. The reduction of beat rate after treatment with neladenoson was reversed by pre-treatment with an $\mathrm{A}_{1} \mathrm{R}$ subtype-selective antagonist, SLV320, indicating that this effect is $\mathrm{A}_{1} \mathrm{R}$-mediated (Figure 6A).

In rat isolated right atria, neladenoson and VCP746 had a minimal effect on the beat rate in contrast to NECA, which decreased beat rate in a concentration-dependent manner $\left(\mathrm{pIC}_{50}\right.$
$=7.5 \pm 0.3, \mathrm{n}=8$; Figure 6B). By using AR subtype-specific agonists and the $A_{1} R$ specific antagonist SLV320 we confirmed that the bradycardic response was also almost entirely $\mathrm{A}_{1} \mathrm{R}$-mediated. The $\mathrm{A}_{1} \mathrm{R}$ selective agonist 2-Me-CCPA maximally inhibited beat rate in a manner similar to the nonselective agonist, NECA, whereas CGS21680 ( $\mathrm{A}_{2 \mathrm{~A}} \mathrm{R}$ selective) or BAY60-6583 ( $\mathrm{A}_{2 \mathrm{~B}} \mathrm{R}$ selective) had no significant effect in the same concentration range (Supplementary Figure S4A). Additionally, pre-treatment with the selective $A_{1} R$ antagonist SLV320, abrogated the chronotropic effect of NECA, further confirming the involvement of $A_{1} R$ (Supplementary Figure S4B).

Likewise, in conscious rats, increasing plasma concentrations of NECA reduced telemetered heart rate in a concentrationdependent manner $\left(\mathrm{pIC}_{50}=6.9 \pm 0.2, \mathrm{n}=6\right.$; Figure $6 \mathrm{C}$ ). Neladenoson $(1 \mu \mathrm{M})$ produced a decrease in heart rate, whereas VCP746 (1-3 $\mu \mathrm{M})$ produced a modest, concentrationdependent increase in heart rate (Figure 6C).

Collectively the data show that AR-mediated chronotropic effects are $A_{1} R$-dependent and suggest that, unlike prototypical AR agonists, biased agonists such as VCP746 and neladenoson have limited effects on cardiomyocyte or isolated atria beat rate $e x$ vivo, and heart rate in rodents in vivo, further strengthening the link between the bias profile of both of these compounds and the lack of chronotropic effects, thus providing a potential route for avoidance of on-target mediated side effects.

\section{VCP746 and Neladenoson Induce Renal Vasodilation by $A_{2 B} R$ Agonist Activity}

Patients with heart failure exhibit abnormal cardio-renal hemodynamics that ultimately exacerbates the disease. 

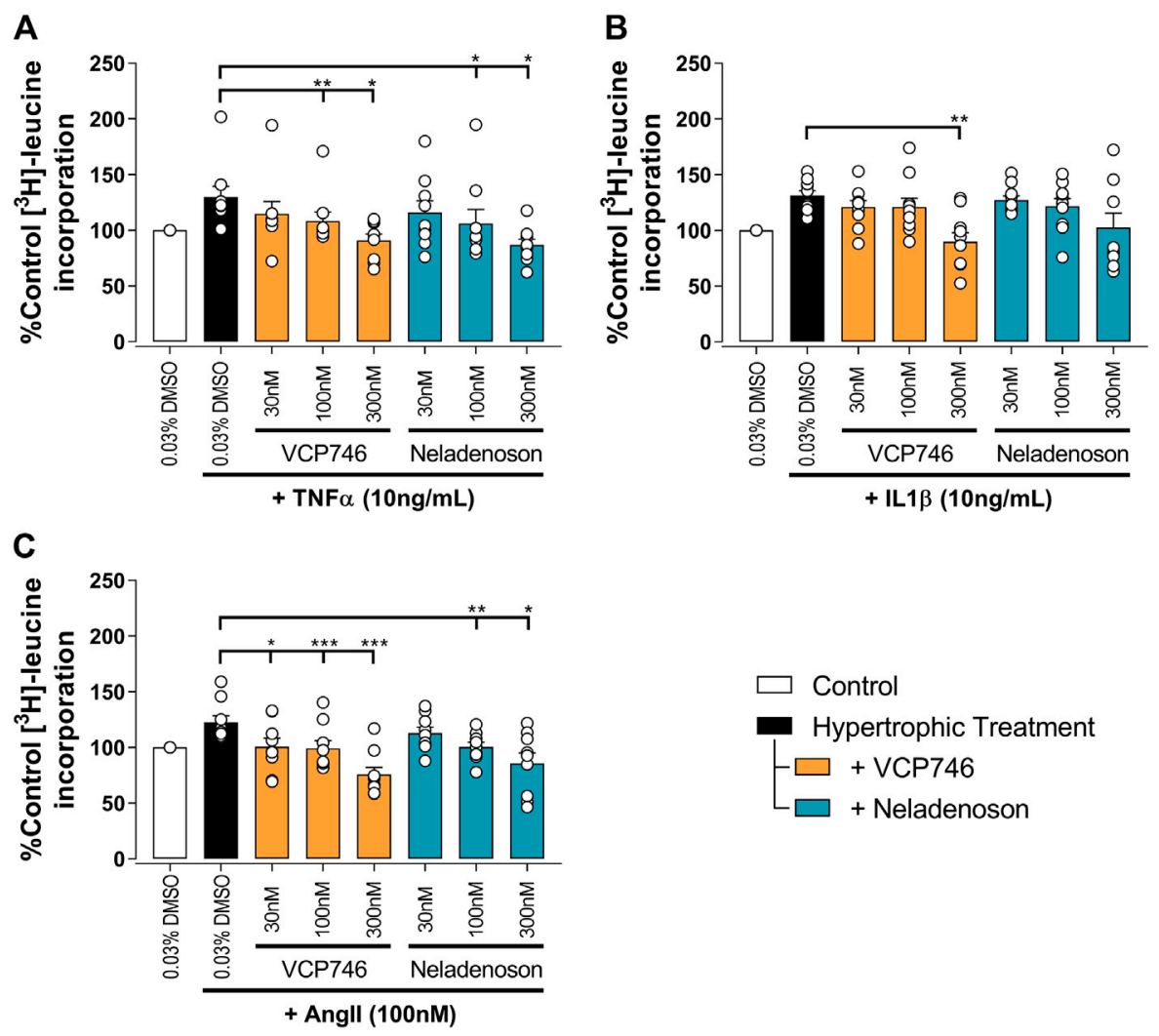

FIGURE 4 | VCP746 and neladenoson reduce cardiomyocyte hypertrophy. Rat primary neonatal ventricular cardiomyocytes were exposed to hypertrophic stimuli TNF $\alpha$ (10 ng/ml; A; $n=9)$, IL1 $\beta$ (10 ng/ml; B; $n=10)$ or Angll (100 nM; C; $n=9)$ for $72 \mathrm{~h}$ after $2 \mathrm{~h}$ pretreatment with the indicated adenosine receptor agonists. Hypertrophy was assessed by incorporation of ${ }^{3} \mathrm{H}$-leucine as an indicator of protein synthesis. Statistical significance was assessed by repeated measures one-way ANOVA with Dunnett's multiple comparisons, compared with hypertrophic treatment (black bar) alone $\left({ }^{\star} p<0.05,{ }^{\star *} p<0.01,{ }^{\star \star *} p<0.001\right)$.
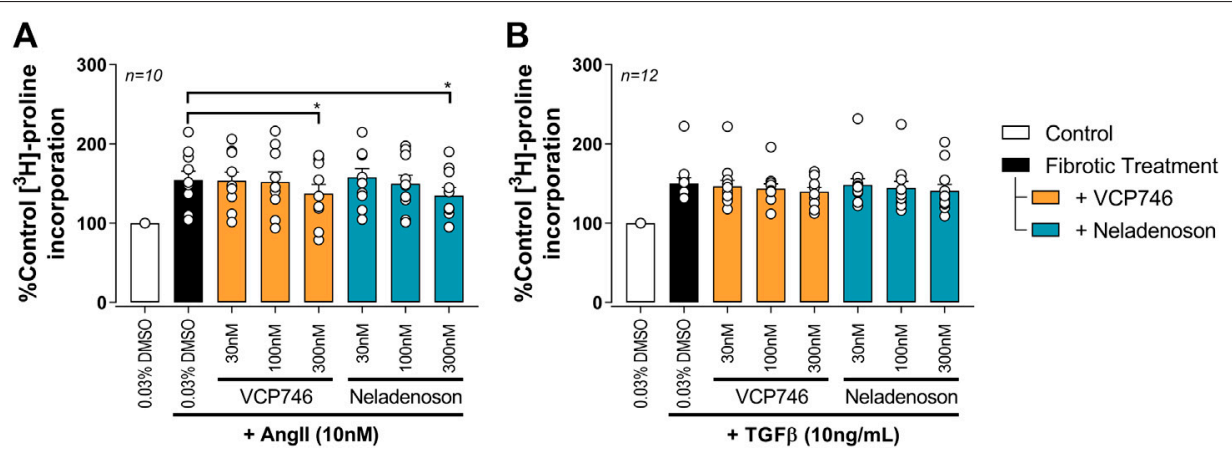

FIGURE 5 | Adenosinergic agonists show some anti-fibrotic activity in rat primary neonatal cardiac fibroblasts. Fibrosis was measured by the incorporation of ${ }^{3} \mathrm{H}$-proline as an indicator of collagen formation. After $72 \mathrm{~h} 10 \mathrm{nM}$ Angll (A) or $10 \mathrm{ng} / \mathrm{ml}$ TGF $\beta$ (B) treatment, VCP746 and neladenoson pre-treatment (2 h) inhibited the Angll-fibrotic effect only, at $300 \mathrm{nM}$ (repeated measures one-way ANOVA, Dunnett's multiple comparisons, in comparison to fibrotic treatment alone; * $(p<0.05)$ ).

Adenosine receptors play an important role in the hemodynamic balance in the kidney; adenosine induces $\mathrm{A}_{1} \mathrm{R}$-mediated cortical vasoconstriction and $\mathrm{A}_{2 \mathrm{~A}} \mathrm{R} /$ $\mathrm{A}_{2 \mathrm{~B}} \mathrm{R}$-mediated medullar vasodilation, reducing filtration fraction in order to recover from negative energy balance in the kidney. Accordingly, effects in the kidney may potentially have implications for any adenosine receptor agonist synthesized for clinical use.

Using the $\alpha_{1}$-adrenoceptor agonist methoxamine to elevate vascular tone, we investigated renal vasodilation. The adenosine $\mathrm{A}_{2 \mathrm{~B}} \mathrm{R}$ agonist BAY 60-6583, VCP746, and neladenoson all induced vasodilation, with a potency $\left(\mathrm{pEC}_{50}\right)$ of order VCP746 

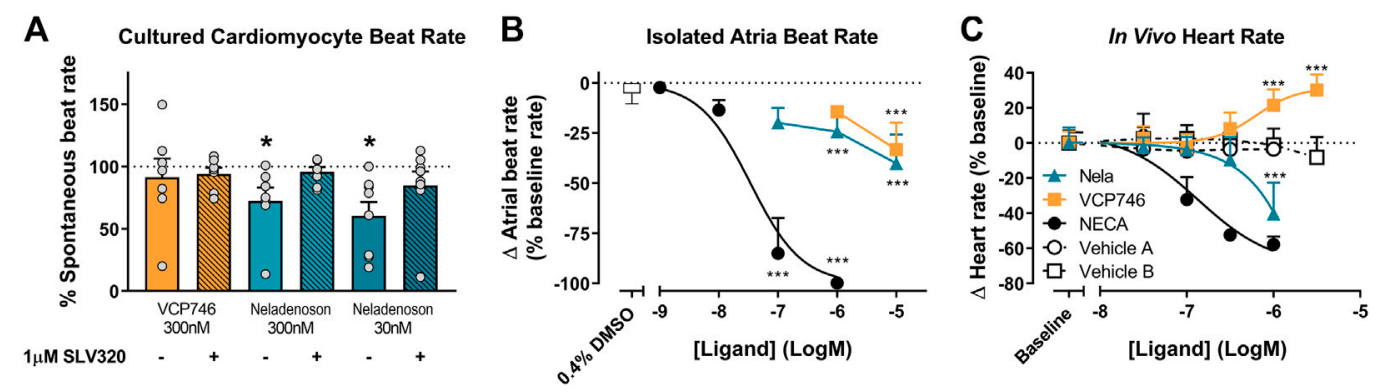

FIGURE 6 | Ex vivo and in vivo $A_{1} R$-mediated chronotropic effects. In isolated neonatal ventricular cardiomyocytes, VCP746 $(n=7)$ had no effect on the spontaneous contraction rate of cells (A), while neladenoson (30 nM: $n=7 ; 300 n M: n=8$ ) showed a significant depressive effect, which is completely abrogated by pretreatment with the $A_{1} R$ antagonist SLV320 (statistics were performed on raw data; paired Student's t-test, comparison of VCP746/neladenoson-treated cells to the same cells prior to treatment; $\left.{ }^{*}(p<0.05)\right)$. Data are mean \pm SEM. In isolated atria (B), NECA produced a concentration-dependent effect $(n=8)$, while only minor effects of VCP746/neladenoson ( $n=4-9)$ were observed at high concentrations (1 or $10 \mu \mathrm{M}$; one-way ANOVA compared with vehicle alone; ${ }^{* \star \star}(p<0.01)$ ). (C) Adenosinergic compounds were also tested in vivo. NECA $(n=6)$ decreased heart rate relative to vehicle $A(n=2)$. Neladenoson $(n=4)$ significantly reduced heart rate at $1 \mu \mathrm{M}$ relative to vehicle $B(n=7)$, while VCP746 $(n=5)$ increased heart rate at high concentrations in vivo (two-way ANOVA, Sidak's multiple comparisons, compared with vehicle B). Data for (B) and (C) are expressed as mean \pm SD.
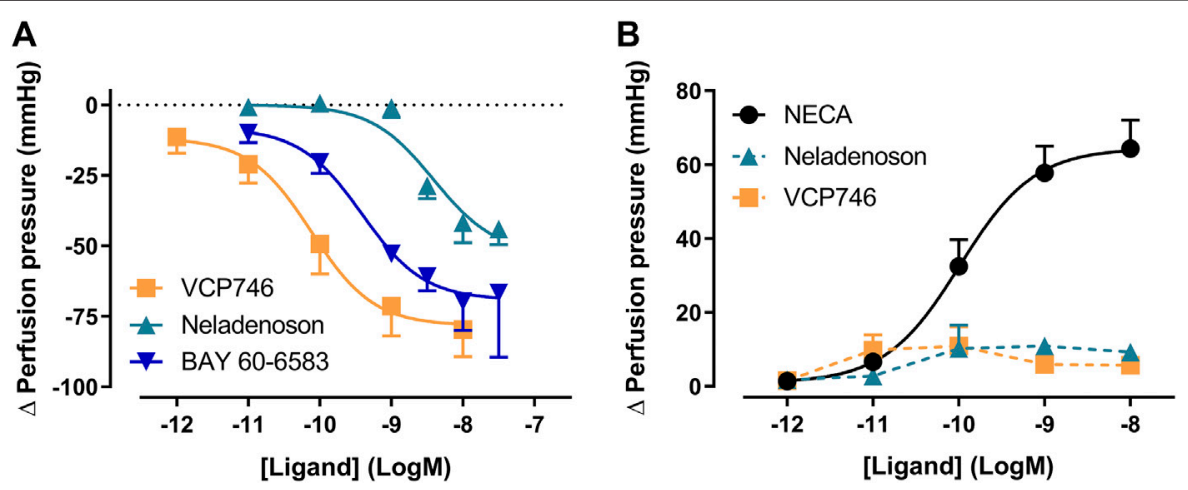

FIGURE 7 | VCP746 and neladenoson induce $A_{2 B} R$-mediated renal vasodilation but no $A_{1} R$-mediated vasoconstriction. (A) Renal vasodilation was measured by administering VCP746 or the $A_{2 A} R / A_{2 B} R$ agonist $B A Y$ 60-6583 to methoxamine-stimulated rat kidney and measuring resulting perfusion pressure $(n=3)$. The concentration-dependent vasodilation produced, with order of potency VCP467 > BAY 60-6583 > neladenson suggest an $A_{2 B} R$-mediated mechanism of action, which was confirmed using selective antagonists (Supplementary Figure S5). (B) In order to measure renal vasoconstriction, kidneys were stimulated with methoxamine/forskolin and then NECA $(n=6)$, neladenoson $(n=6)$ or VCP746 $(n=5)$ was applied. NECA induced a potent constrictor activity, with no response observed to neladenoson/NCP746. This was confirmed to be an $A_{1}$ R-mediated effect (Supplementary Figure S5). Data are expressed as mean \pm SEM; where error bars are not visible, they are contained within the dimensions of the symbol.

$(10.1 \pm 0.3, \mathrm{n}=3)>$ BAY $60-6583(9.4 \pm 0.4, \mathrm{n}=3)>$ neladenoson $(8.4 \pm 0.2, \mathrm{n}=3$; Figure 7A). Since the BAY 60-6583 response is sensitive to MRS1754, but not SCH442426 (Supplementary Figure S5A), it suggests that the response is $A_{2 B} R-$, rather than $\mathrm{A}_{2 \mathrm{~A}} \mathrm{R}$-mediated. This would be consistent with VCP746 showing greater potency and efficacy at the $\mathrm{A}_{2 \mathrm{~B}} \mathrm{R}$ compared with neladenoson (Figures 2, 7A).

In order to study effects on vasoconstriction, methoxaminetreated kidneys were treated with forskolin to activate adenylate cyclase and reduce vascular tone. Under these conditions, NECA induced renal vasoconstriction (Figure $7 \mathbf{B}$ ) in a concentration dependent-manner $\left(\mathrm{pEC}_{50}=10.0 \pm 0.2, \mathrm{n}=6\right)$. Similarly, the $\mathrm{A}_{1} \mathrm{R}$-selective agonist, 2-Me-CCPA, induced a vasoconstrictor response that was abolished by the $A_{1} R$-specific antagonist, SLV320 (Supplementary Figure S5B) indicating that the renal vasodilation is $\mathrm{A}_{1} \mathrm{R}$-dependent. However, VCP746 and neladenoson had no effect on the vasoconstrictor response (Figure 7B). Since the response is sensitive to $A_{1} R$ activation, the lack of effect after VCP746 or neladenoson suggests that the bias profile of these compounds contributes to their lack of renal vasoconstrictor activity.

\section{Neither VCP746 nor Neladenoson Induce Endothelium-dependent Thoracic Aorta Relaxation}

In order to confirm subtype selectivity, VCP746 and neladenoson were tested for effects on rat thoracic aorta relaxation, in the presence and absence of endothelium. NECA relaxed the aorta in an endothelium-dependent $\mathrm{A}_{2 \mathrm{~A}} \mathrm{R}$-mediated manner (Figure 8; Supplementary Figure S6). In contrast, neither VCP746 nor neladenoson had any effect on the aorta (Figure 8), broadly 


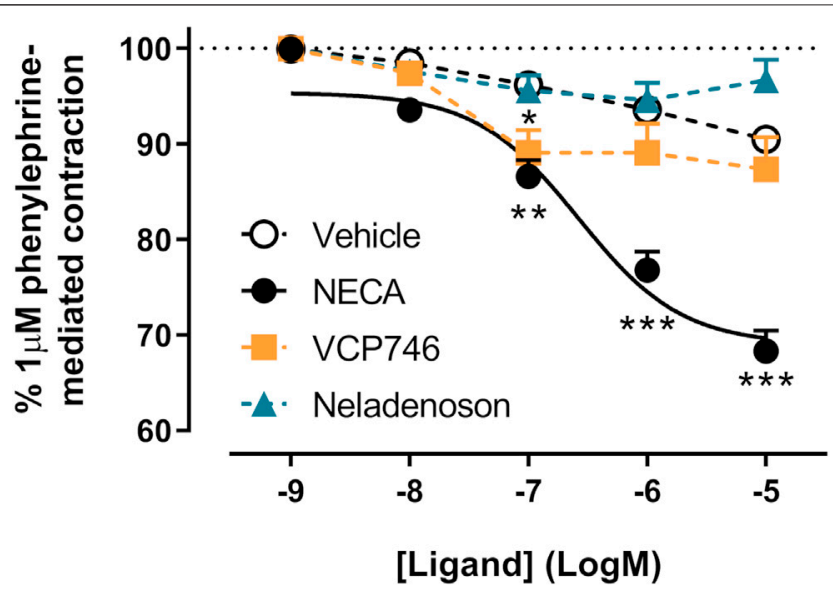

FIGURE 8 | NECA, but not VCP746 or neladenoson induces endothelium-dependent relaxation of rat thoracic aorta. NECA concentrationdependently inhibited phenylephrine-mediated contraction ( $\mathrm{pEC}_{50} 6.6 \pm 0.2$ ) while VCP746 and neladenoson displayed negligible effects $(n=3)$. Antagonist studies suggest this is a predominately $A_{2 A} R$-mediated mechanism (Supplementary Figure S6). Data are expressed as mean \pm SEM; where error bars are not visible, they are contained within the dimensions of the symbol. Statistical significance treatment was assessed by repeated measures mixed effects model with Dunnett's multiple comparisons, compared with vehicle $\left({ }^{\star} p<0.05,{ }^{\star *} p<0.01,{ }^{\star \star *} p<0.001\right)$.

consistent with their relatively low potency (VCP746) or lack of activity (neladenoson) at the $\mathrm{A}_{2 \mathrm{~A}} \mathrm{R}$ (Figure 2).

\section{DISCUSSION}

The $A_{1} R$ has been a focus of heart failure drug discovery efforts for over 2 decades. The cardioprotective effects of adenosine are well described, but efforts to develop selective $A_{1} R$ agonists have been limited by on-target mediated bradycardia, atrioventricular block, and other extra-cardiac undesired effects. Several approaches have been taken to the design of novel agents to mitigate these risks. Bayer developed the $A_{1} R$ partial agonists capadenoson and neladenoson (a pro-drug of an active and more soluble metabolite; Meibom et al., 2017), whereas other preclinical work identified biased $A_{1} R$ agonists that exhibit specific signaling profiles focused on avoiding on-target mediated adverse effects. The $A_{1} R$ subtype is a $G a_{i / o}$-coupled receptor that couples pleiotropically to multiple downstream endpoints, including inhibition of cAMP accumulation, MAPK activation, and increased intracellular calcium mobilization. Thus, linking a signaling pathway (or subset of pathways) to a specific physiological outcome represents a mechanism whereby agents can be developed that avoid on-target side effects on the kidney, peripheral blood vessels, or the heart.

VCP746 is a tool biased $A_{1} R$ agonist that preferentially signals away from intracellular calcium mobilization compared with inhibition of cAMP accumulation (Baltos et al., 2016). Growing evidence points to agonist-induced increases in calcium flux as a predictor of $\mathrm{A}_{1} \mathrm{R}$-mediated side effects (Valant et al., 2014; Baltos et al., 2016; Greene et al., 2016).
We have shown that the $A_{1} R$ bias signaling profile of capadenoson, neladenoson and VCP746 are broadly similar in that they are biased away from stimulation of intracellular calcium mobilization. This phenotype translated to primary cardiomyocytes, isolated rat atria, and in vivo in telemetered rats, where both neladenoson and VCP746 had little effect on beat/heart rate, unlike the prototypical adenosine analogue, NECA. Interestingly, at equi-effective concentrations for $\mathrm{A}_{1} \mathrm{R}$-mediated inhibition of cAMP signaling, neladenoson inhibited the beat rate of ventricular cardiomyocytes and heart rate in vivo in contrast to VCP746, suggesting alternative signaling pathways are involved in this process.

Nonetheless, in the clinic, capadenoson and neladenoson had little effect on heart rate in trials in patients with angina pectoris, atrial fibrillation, or congestive heart failure (Shah et al., 2019; Voors et al., 2019; Clinical Trial NLM Identifiers: NCT00568945, NCT03098979, NCT02992288) suggesting that bias in the cAMP-calcium signaling balance downstream of the $A_{1} R$ is a critical predictor for avoiding bradycardia (Zablocki et al., 2004; Albrecht-Küpper et al., 2012).

A further consideration for $A_{1} R$ agonists is their potential for deleterious effects on renal hemodynamics and a number of groups have developed $\mathrm{A}_{1} \mathrm{R}$ antagonists for the treatment of impaired renal function in congestive heart failure (Vallon et al., 2008). This approach was predicated on stimulating renal vessel relaxation and inhibiting the tubuloglomerular feedback mechanism, thus increasing urine output without worsening glomerular filtration rate. Such a mechanism suggests that $\mathrm{A}_{1} \mathrm{R}$ agonists might impair renal function. However, our studies show that VCP746 and neladenoson lack renal vasoconstrictor effects in the methoxamine/forskolintreated kidney. Again, this indicates that the signaling profile at the $A_{1} R$ and/or ancillary pharmacology of these two agents is beneficial when compared with non-selective/non-biased adenosine receptor agonists that cause vasoconstriction. In fact, both neladenoson and VCP746 caused renal vasorelaxation, mediated by the adenosine $A_{2 B}$ receptor, which explains the 30 -fold discrepancy in potency between the two agents in favor of VCP746. In turn this offers a potential explanation for the small, concentration-dependent increase in heart rate observed with VCP746 in vivo that may well be a compensatory response to the increased renal vasorelaxation whilst the rats remain normotensive.

Clinically, neladenoson either had no (Shah et al., 2019) or marginal (Voors et al., 2019) effects on heart rate, a profile largely predicted by pre-clinical models. However, the compound failed to improve cardiac and non-cardiac abnormalities in phase II trials in heart failure patients with either preserved or reduced ejection fraction, and slightly worsened renal function in the latter population (Shah et al., 2019; Voors et al., 2019). This clearly differs from the pre-clinical profile, where neladenoson was cardioprotective in a left anterior descending artery occlusion-induced ischemia model in rats (Meibom et al., 2017).

The failure of neladenoson in these clinical trials poses a number of questions for adenosine receptor-targeting heart failure therapeutics. Despite the clinically-proven 
cardioprotective effects of adenosine (McIntosh and Lasley, 2012; Headrick et al., 2013; Randhawa and Jaggi, 2016), it might be that selective $A_{1} R$ activation, differential $A_{1} R$ bias, or targeting patients with chronic, rather than acute, heart failure, could be responsible for the lack of efficacy of neladenoson. Whilst neladenoson has the critical cAMP-calcium bias required for improving therapeutic index, it is also highly biased away from the MAPK pathways, ERK1/2 and Akt1/2/3 phosphorylation. This may be undesirable since ERK1/2 phosphorylation plays a role in cardioprotection (Germack and Dickenson, 2005; Reid et al., 2005; Kovacs et al., 2009; Rose et al., 2010), while Akt1/2/3 phosphorylation is generally considered a pro-survival pathway utilized by many cardioprotective agents (Matsui and Rosenzweig, 2005; Solenkova et al., 2006; Manning and Cantley, 2007; Kovacs et al., 2009). It remains to be seen whether therapeutic agents can be developed that have $A_{1} R$ cAMP-calcium bias, without the bias away from MAPK signaling. This signaling profile may explain the greater potency of VCP746 in reducing humoral- and inflammationinduced cardiomyocyte hypertrophy compared with neladenoson - herein and (Chuo et al., 2016) - despite neladenoson being more potent than VCP746 for cAMP inhibition.

With respect to selectivity, our recombinant cell signaling data showed that neladenoson activated neither the $\mathrm{A}_{2 \mathrm{~A}} \mathrm{R}$ or $A_{3} R$ subtypes, and (unlike VCP746) is a biased agonist at the $\mathrm{A}_{2 \mathrm{~B}} \mathrm{R}$ (away from MAPK while calcium signaling was undetectable). Activation of $\mathrm{A}_{2 \mathrm{~B}} \mathrm{R}$ reduces fibrosis in heart failure (Dubey et al., 1997, 1998, 2001; Chen et al., 2004), though the signaling pathway(s) responsible for this are not well defined. Here we showed equivalence for neladenoson and VCP746 for anti-fibrotic efficacy in cardiac fibroblasts, and previous studies have shown that VCP746 exhibits potent $\mathrm{A}_{2 \mathrm{~B}} \mathrm{R}$-dependent anti-fibrotic activity (Vecchio et al., 2016a). Thus, appropriate $A_{2 B} R$ signaling profiles for adenosine receptor agonists may be required in heart failure therapeutics. These issues of selectivity and bias are important in the context of treating chronic, as opposed to acute, heart failure, where anti-hypertrophic and antifibrotic activity would be desirable. Additionally, the lack of clinical translation calls into question the predictive capacity of rodent models of heart failure (Houser et al., 2012) or their translation to specific stages of the disease in patients.

The concept of biased agonism faces a number of challenges in linking signaling profiles to clinical endpoints and improved therapeutic indices. Despite promising preclinical data, biased agonists have yet to fulfill their full promise in the clinic: the $\beta$-arrestin-biased angiotensin AT1 receptor agonist, TRV 027, failed to meet its primary endpoint in a phase IIb study of patients with acute heart failure (Pang et al., 2017). In addition to improving the pre-clinical assessment of what constitutes a biased agonist (e.g. for $\mu$-opioid receptors (Conibear and Kelly, 2019)), it is critical to understand the pharmacology of agents that have been developed and clinically-evaluated without reference to the phenomenon of signal bias. In this study we comprehensively compared in vitro, ex vivo, and in vivo properties of the investigational $A_{1} R$ agonist, neladenoson, compared to VCP746, a tool $A_{1} R$ biased agonist. Retrospective analysis of the signaling profile of neladenoson reinforces the cellular predictor (cAMP-calcium signaling bias) for its lack of effect on heart rate in pre-clinical models and patients. Although the reasons for the lack of clinical efficacy remain unknown, it is possible that fine tuning activity in other pathways (e.g. MAPK) and/or adenosine receptors (e.g. $A_{2 B} R$ ) might represent valid future approaches for the development of novel agents.

\section{DATA AVAILABILITY STATEMENT}

The raw data supporting the conclusions of this article will be made available by the authors, without undue reservation.

\section{ETHICS STATEMENT}

The animal study was reviewed and approved by the Animal Ethics Committee, Servier, and Monash Institute of Pharmaceutical Sciences Animal Ethics Committee (MIPS.2017.18).

\section{AUTHOR CONTRIBUTIONS}

PR and JM performed all signaling assays, all experiments in isolated cardiomyocytes and cardiac fibroblasts and all subsequent analysis. SC managed in vivo experiments. JP and MF managed isolated aorta, kidney and atria experiments. PR, JM and CJL prepared the manuscript and PMS, SC and JP provided feedback on the manuscript. PJW, AC, WNC, RJS, PMS, LTM, SC, JP and MF provided feedback throughout the project.

\section{FUNDING}

This study was partially funded by Servier as part of a collaborative research program focused on biased adenosine receptor agonists for the potential treatment of heart failure. LTM is an Australian Heart Foundation Future Leaders Fellow; PMS and AC are/were NHMRC Senior Principal Research Fellows.

\section{ACKNOWLEDGMENTS}

The authors would like to thank Joanne Baltos, Elizabeth Vecchio and Anh Nguyen for gift of the CHO cells, Cameron Nowell for help with implementation of Image J analysis for beat rate studies, and Isabelle Lapret and Denis Gransagne for their excellent technical assistance on in vitro/ex vivo and in vivo experiments, respectively. LTM is an Australian Heart Foundation Future Leaders Fellow and PMS and AC are/were NHMRC Senior Principal Research Fellows. This manuscript was 
previously published on bioRxiv (https:/www.biorxiv.org/ content/10.1101/2020.07.22.215509v2.full). The authors would like to dedicate this manuscript to the memory of the late Prof. Paul Vanhoutte, whose advocacy and insights inspired this collaborative study.

\section{REFERENCES}

Albrecht-Küpper, B. E., Leineweber, K., and Nell, P. G. (2012). Partial adenosine A1 receptor agonists for cardiovascular therapies. Purinergic Signal. 8, 91-99. doi:10.1007/s11302-011-9274-3

Arunlakshana, O., and Schild, H. O. (1959). Some quantitative uses of drug antagonists. Br. J. Pharmacol. Chemother. 14, 48-58. doi:10.1111/j.14765381.1959.tb00928.x

Baltos, J. A., Gregory, K. J., White, P. J., Sexton, P. M., Christopoulos, A., and May, L. T. (2016). Quantification of adenosine A1 receptor biased agonism: implications for drug discovery. Biochem. Pharmacol. 99, 101-112. doi:10. 1016/j.bcp.2015.11.013

Belardinelli, L., Shryock, J. C., Song, Y., Wang, D., and Srinivas, M. (1995). Ionic basis of the electrophysiological actions of adenosine on cardiomyocytes. FASEB J. 9, 359-365. doi:10.1096/fasebj.9.5.7896004

Bertero, E., and Maack, C. (2019). The Partial AdeNosine A1 receptor agonist in patients with Chronic Heart failure and preserved Ejection fraction (PANACHE) trial. Cardiovasc. Res. 115, e71-e73. doi:10.1093/cvr/cvz123

Bonsu, K. O., Arunmanakul, P., and Chaiyakunapruk, N. (2018). Pharmacological treatments for heart failure with preserved ejection fraction-a systematic review and indirect comparison. Heart Fail. Rev. 23, 147-156. doi:10.1007/s10741018-9679-y

Brust, T. F., Hayes, M. P., Roman, D. L., Burris, K. D., and Watts, V. J. (2015). Bias analyses of preclinical and clinical D2 dopamine ligands: studies with immediate and complex signaling pathways. J. Pharmacol. Exp. Ther. 352, 480-493. doi:10.1124/jpet.114.220293

Cabiati, M., Martino, A., Mattii, L., Caselli, C., Prescimone, T., Lionetti, V., et al. (2014). Adenosine receptor expression in an experimental animal model of myocardial infarction with preserved left ventricular ejection fraction. Heart Vessels 29, 513-519. doi:10.1007/s00380-013-0380-8

Chen, Y., Epperson, S., Makhsudova, L., Ito, B., Suarez, J., Dillmann, W., et al. (2004). Functional effects of enhancing or silencing adenosine A2b receptors in cardiac fibroblasts. Am. J. Physiol. Heart Circ. Physiol. 287, H2478-H2486. doi:10.1152/ajpheart.00217.2004

Chuo, C. H., Devine, S. M., Scammells, P. J., Krum, H., Christopoulos, A., May, L. T., et al. (2016). VCP746, a novel A1 adenosine receptor biased agonist, reduces hypertrophy in a rat neonatal cardiac myocyte model. Clin. Exp. Pharmacol. Physiol. 43, 976-982. doi:10.1111/1440-1681.12616

Conibear, A. E., and Kelly, E. (2019). A biased view of $\mu$-opioid receptors?. Mol. Pharmacol. 96, 542-549. doi:10.1124/mol.119.115956

Coronel, R., De Groot, J. R., and Van Lieshout, J. J. (2001). Defining heart failure. Cardiovasc. Res. 50, 419-422. doi:10.1016/S0008-6363(01)00284-X

Damman, K., and Testani, J. M. (2015). The kidney in heart failure: an update. Eur. Heart J. 36, 1437-1444. doi:10.1093/eurheartj/ehv010

DeWire, S. M., Yamashita, D. S., Rominger, D. H., Liu, G., Cowan, C. L., Graczyk, T. M., et al. (2013). A G protein-biased ligand at the $\mu$-opioid receptor is potently analgesic with reduced gastrointestinal and respiratory dysfunction compared with morphine. J. Pharmacol. Exp. Ther. 344, 708-717. doi:10.1124/ jpet.112.201616

Dubey, R. K., Gillespie, D. G., and Jackson, E. K. (1998). Adenosine inhibits collagen and protein synthesis in cardiac fibroblasts: role of A2b receptors. Hypertension 31, 943-948. doi:10.1161/01.HYP.31.4.943

Dubey, R. K., Gillespie, D. G., Mi, Z., and Jackson, E. K. (1997). Exogenous and endogenous adenosine inhibits fetal calf serum-induced growth of rat cardiac fibroblasts: role of A2B receptors. Circulation 96, 2656-2666. doi:10.1161/01. CIR.96.8.2656

Dubey, R. K., Gillespie, D. G., Zacharia, L. C., Mi, Z., and Jackson, E. K. (2001). A2b receptors mediate the antimitogenic effects of adenosine in cardiac fibroblasts. Hypertension 37, 716-721. doi:10.1161/01.hyp.37.2.716

\section{SUPPLEMENTARY MATERIAL}

The Supplementary Material for this article can be found online at: https://www.frontiersin.org/articles/10.3389/fphar.2021.628060/ full\#supplementary-material.

Epperson, S. A., Brunton, L. L., Ramirez-Sanchez, I., and Villarreal, F. (2009). Adenosine receptors and second messenger signaling pathways in rat cardiac fibroblasts. Am. J. Physiol. Cel Physiol 296, C1171-C1177. doi:10.1152/ajpcell. 00290.2008

Erten, Y., Tulmac, M., Derici, U., Pasaoglu, H., Altok Reis, K., Bali, M., et al. (2005). An association between inflammatory state and left ventricular hypertrophy in hemodialysis patients. Ren. Fail. 27, 581-589. doi:10.1080/08860220500200072

Fredholm, B. B., IJzerman, A. P., Jacobson, K. A., Linden, J., and Müller, C. E. (2011). International union of basic and clinical pharmacology. LXXXI. Nomenclature and classification of adenosine receptors--an update. Pharmacol. Rev. 63, 1-34. doi:10.1124/pr.110.003285

Frey, N., and Olson, E. N. (2003). Cardiac hypertrophy: the good, the bad, and the ugly. Annu. Rev. Physiol. 65, 45-79. doi:10.1146/annurev.physiol.65.092101. 142243

Germack, R., and Dickenson, J. (2005). Adenosine triggers preconditioning through $\mathrm{MEK} / \mathrm{ERK} 1 / 2$ signalling pathway during hypoxia/reoxygenation in neonatal rat cardiomyocytes. J. Mol. Cel Cardiol 39, 429-442. doi:10.1016/j. yjmcc.2005.06.001

Germack, R., and Dickenson, J. M. (2004). Characterization of ERK1/2 signalling pathways induced by adenosine receptor subtypes in newborn rat cardiomyocytes. Br. J. Pharmacol. 141, 329-339. doi:10.1038/sj.bjp.0705614

Greene, S. J., Sabbah, H. N., Butler, J., Voors, A. A., Albrecht-Küpper, B. E., Düngen, H. D., et al. (2016). Partial adenosine A1 receptor agonism: a potential new therapeutic strategy for heart failure. Heart Fail. Rev. 21, 95-102. doi:10. 1007/s10741-015-9522-7

Headrick, J. P., Ashton, K. J., Rose'meyer, R. B., and Peart, J. N. (2013). Cardiovascular adenosine receptors: expression, actions and interactions. Pharmacol. Ther. 140, 92-111. doi:10.1016/j.pharmthera.2013.06.002

Heidenreich, P. A., Albert, N. M., Allen, L. A., Bluemke, D. A., Butler, J., Fonarow, G. C., et al. (2013). Forecasting the impact of heart failure in the United States a policy statement from the american heart association. Circ. Heart Fail. 6, 606-619. doi:10.1161/HHF.0b013e318291329a

Houser, S. R., Margulies, K. B., Murphy, A. M., Spinale, F. G., Francis, G. S., Prabhu, S. D., et al. (2012). Animal models of heart failure: a scientific statement from the American Heart Association. Circ. Res. 111, 131-150. doi:10.1161/RES 0b013e3182582523

Jessup, M., Marwick, T. H., Ponikowski, P., Voors, A. A., and Yancy, C. W. (2016). 2016 ESC and ACC/AHA/HFSA heart failure guideline update - what is new and why is it important?. Nat. Rev. Cardiol. 13, 623-628. doi:10.1038/nrcardio. 2016.134

Kemp, B. K., and Cocks, T. M. (1999). Adenosine mediates relaxation of human small resistance-like coronary arteries via $\mathrm{A}(2 \mathrm{~B})$ receptors. $\mathrm{Br}$. J. Pharmacol. 126, 1796-1800. doi:10.1038/sj.bjp.0702462

Kenakin, T., and Christopoulos, A. (2013). Signalling bias in new drug discovery: detection, quantification and therapeutic impact. Nat. Rev. Drug Discov. 12, 205-216. doi:10.1038/nrd3954

Kenakin, T. P., and Pike, N. B. (1987). An in vitro analysis of purine-mediated renal vasoconstriction in rat isolated kidney. Br. J. Pharmacol. 90, 373-381. doi:10. 1111/j.1476-5381.1987.tb08967.x

Kovacs, J. J., Hara, M. R., Davenport, C. L., Kim, J., and Lefkowitz, R. J. (2009). Arrestin development: emerging roles for $\beta$-arrestins in developmental signaling pathways. Dev. Cel. 17, 443-458. doi:10.1016/j.devcel.2009.09.011

Kuusisto, J., Kärjä, V., Sipola, P., Kholová, I., Peuhkurinen, K., Jääskeläinen, P., et al. (2012). Low-grade inflammation and the phenotypic expression of myocardial fibrosis in hypertrophic cardiomyopathy. Heart 98, 1007-1013. doi:10.1136/heartjnl-2011-300960

Liao, Y., Lin, L., Lu, D., Fu, Y., Bin, J., Xu, D., et al. (2011). Activation of adenosine A1 receptor attenuates tumor necrosis factor- $\alpha$ induced hypertrophy of cardiomyocytes. Biomed. Pharmacother. 65, 491-495. doi:10.1016/j.biopha. 2011.06.008 
Linden, J. (2005). Adenosine in tissue protection and tissue regeneration. Mol. Pharmacol. 67, 1385-1387. doi:10.1124/mol.105.011783

Mallipeddi, S., Janero, D. R., Zvonok, N., and Makriyannis, A. (2017). Functional selectivity at G-protein coupled receptors: advancing cannabinoid receptors as drug targets. Biochem. Pharmacol. 128, 1-11. doi:10.1016/j.bcp.2016.11.014

Manning, B. D., and Cantley, L. C. (2007). AKT/PKB signaling: navigating downstream. Cell 129, 1261-1274. doi:10.1016/j.cell.2007.06.009

Matsui, T., and Rosenzweig, A. (2005). Convergent signal transduction pathways controlling cardiomyocyte survival and function: the role of PI 3-kinase and Akt. J. Mol. Cel Cardiol 38, 63-71. doi:10.1016/j.yjmcc.2004.11.005

McIntosh, V. J., and Lasley, R. D. (2012). Adenosine receptor-mediated cardioprotection: are all 4 subtypes required or redundant?. J. Cardiovasc. Pharmacol. Ther. 17, 21-33. doi:10.1177/1074248410396877

Meibom, D., Albrecht-Küpper, B., Diedrichs, N., Hübsch, W., Kast, R., Krämer, T., et al. (2017). Neladenoson bialanate hydrochloride: a prodrug of a partial adenosine A1 receptor agonist for the chronic treatment of heart diseases. ChemMedChem 12, 728-737. doi:10.1002/cmdc.201700151

Mores, K. L., Cummins, B. R., Cassell, R. J., and van Rijn, R. M. (2019). A review of the therapeutic potential of recently developed $\mathrm{G}$ protein-biased kappa agonists. Front. Pharmacol. 10, 407-414. doi:10.3389/fphar.2019.00407

Mozaffarian, D., Benjamin, E. J., Go, A. S., Arnett, D. K., Blaha, M. J., Cushman, M., et al. (2015). Heart disease and stroke statistics-2015 update: a report from the American heart association. Circulation 131 (4), e29-322. doi:10.1161/CIR. 0000000000000152

Owan, T. E., Hodge, D. O., Herges, R. M., Jacobsen, S. J., Roger, V. L., and Redfield, M. M. (2006). Trends in prevalence and outcome of heart failure with preserved ejection fraction. N. Engl. J. Med. 355, 251-259. doi:10.1056/NEJMoa052256

Pang, P. S., Butler, J., Collins, S. P., Cotter, G., Davison, B. A., Ezekowitz, J. A., et al. (2017). Biased ligand of the angiotensin II type 1 receptor in patients with acute heart failure: a randomized, double-blind, placebo-controlled, phase IIB, dose ranging trial (BLAST-AHF). Eur. Heart J. 38, 2364-2373. doi:10.1093/ eurheartj/ehx196

Ponikowski, P., Voors, A. A., Anker, S. D., Bueno, H., Cleland, J. G., Coats, A. J., et al. (2016). 2016 ESC Guidelines for the diagnosis and treatment of acute and chronic heart failure. Eur. Heart J. 37, 2129-2200. doi:10.1093/eurheartj/ ehw128

Puhl, S. L., Kazakov, A., Müller, A., Fries, P., Wagner, D. R., Böhm, M., et al. (2016). Adenosine A1 receptor activation attenuates cardiac hypertrophy and fibrosis in response to al-adrenoceptor stimulation in vivo. Br. J. Pharmacol. 173, 88-102. doi:10.1111/bph.13339

Randhawa, P. K., and Jaggi, A. S. (2016). Unraveling the role of adenosine in remote ischemic preconditioning-induced cardioprotection. Life Sci. 155, 140-146. doi:10.1016/j.lfs.2016.05.009

Reid, E. A., Kristo, G., Yoshimura, Y., Ballard-Croft, C., Keith, B. J., Mentzer, R. M., et al. (2005). In vivo adenosine receptor preconditioning reduces myocardial infarct size via subcellular ERK signaling. Am. J. Physiol. Heart Circ. Physiol. 288, H2253-H2259. doi:10.1152/ajpheart.01009.2004

Rose, B. A., Force, T., and Wang, Y. (2010). Mitogen-activated protein kinase signaling in the heart: angels versus demons in a heart-breaking tale. Physiol. Rev. 90, 1507-1546. doi:10.1152/physrev.00054.2009

Sabbah, H. N., Gupta, R. C., Kohli, S., Wang, M., Rastogi, S., Zhang, K., et al. (2013). Chronic therapy with a partial adenosine A1-receptor agonist improves left ventricular function and remodeling in dogs with advanced heart failure. Circ. Heart Fail. 6, 563-571. doi:10.1161/CIRCHEARTFAILURE.112.000208

Sato, A., Terata, K., Miura, H., Toyama, K., Loberiza, F. R., Hatoum, O. A., et al. (2005). Mechanism of vasodilation to adenosine in coronary arterioles from patients with heart disease. Am. J. Physiol. Heart Circ. Physiol. 288, H1633-H1640. doi:10.1152/ajpheart.00575.2004

Shah, S. J., Voors, A. A., McMurray, J. J. V., Kitzman, D. W., Viethen, T., Bomfim Wirtz, A., et al. (2019). Effect of neladenoson bialanate on exercise capacity among patients with heart failure with preserved ejection fraction. JAMA 321, 2101. doi:10.1001/jama.2019.6717

Solenkova, N. V., Solodushko, V., Cohen, M. V., and Downey, J. M. (2006). Endogenous adenosine protects preconditioned heart during early minutes of reperfusion by activating Akt. Am. J. Physiol. Heart Circ. Physiol. 290, H441-H449. doi:10.1152/ajpheart.00589.2005

Stewart, G. D., Valant, C., Dowell, S. J., Mijaljica, D., Devenish, R. J., Scammells, P. J., et al. (2009). Determination of adenosine A1 receptor agonist and antagonist pharmacology using Saccharomyces cerevisiae: implications for ligand screening and functional selectivity. J. Pharmacol. Exp. Ther. 331, 277-286. doi:10.1124/ jpet.109.158667

Vaduganathan, M., Butler, J., Pitt, B., and Gheorghiade, M. (2015). Contemporary drug development in heart failure: call for Hemodynamically neutral therapies. Circ. Heart Fail. 8, 826-831. doi:10.1161/CIRCHEARTFAILURE.115.002271

Valant, C., May, L. T., Aurelio, L., Chuo, C. H., White, P. J., Baltos, J. A., et al. (2014). Separation of on-target efficacy from adverse effects through rational design of a bitopic adenosine receptor agonist. Proc. Natl. Acad. Sci. USA 111, 4614-4619. doi:10.1073/pnas.1320962111

Vallon, V., Miracle, C., and Thomson, S. (2008). Adenosine and kidney function: potential implications in patients with heart failure. Eur. J. Heart Fail. 10, 176-187. doi:10.1016/j.ejheart.2008.01.010

Van Der Westhuizen, E. T., Breton, B., Christopoulos, A., and Bouvier, M. (2014). Quantification of ligand bias for clinically relevant $\beta 2$-adrenergic receptor ligands: implications for drug taxonomy. Mol. Pharmacol. 85, 492-509. doi:10.1124/mol.113.088880

Vecchio, E. A., Chuo, C. H., Baltos, J. A., Ford, L., Scammells, P. J., Wang, B. H., et al. (2016a). The hybrid molecule, VCP746, is a potent adenosine A2B receptor agonist that stimulates anti-fibrotic signalling. Biochem. Pharmacol. 117, 46-56. doi:10.1016/j.bcp.2016.08.007

Vecchio, E. A., Tan, C. Y., Gregory, K. J., Christopoulos, A., White, P. J., and May, L. T. (2016b). Ligand-independent adenosine A2B receptor constitutive activity as a promoter of prostate cancer cell proliferation. J. Pharmacol. Exp. Ther. 357, 36-44. doi:10.1124/jpet.115.230003

Voors, A. A., Bax, J. J., Hernandez, A. F., Wirtz, A. B., Pap, A. F., Ferreira, A. C., et al. (2019). Safety and efficacy of the partial adenosine A1 receptor agonist neladenoson bialanate in patients with chronic heart failure with reduced ejection fraction: a phase IIb, randomized, double-blind, placebo-controlled trial. Eur. J. Heart Fail. 21, 1426-1433. doi:10.1002/ejhf.1591

Voors, A. A., Düngen, H. D., Senni, M., Nodari, S., Agostoni, P., Ponikowski, P., et al. (2017). Safety and tolerability of neladenoson bialanate, a novel oral partial adenosine A1 receptor agonist, in patients with chronic heart failure. J. Clin. Pharmacol. 57, 440-451. doi:10.1002/jcph.828

Yang, J. N., Tiselius, C., Daré, E., Johansson, B., Valen, G., and Fredholm, B. B. (2007). Sex differences in mouse heart rate and body temperature and in their regulation by adenosine A1 receptors. Acta Physiol. (Oxf) 190, 63-75. doi:10. 1111/j.1365-201X.2007.01690.x

Zablocki, J., Wu, L., Shryock, J., and Belardinelli, L. (2004). Partial Al adenosine receptor agonists from a molecular perspective and their potential use as chronic ventricular rate control agents during atrial fibrillation (AF). Curr. Top. Med. Chem. 4, 839-854. doi:10.2174/1568026043450998

Conflicts of Interests: SC, JP and MF are/were employees of Servier, a pharmaceutical company engaged the development of new heart failure therapeutics. As indicated above, this study was partially funded by Servier as a collaborative program between Monash University and Servier to investigate G protein-coupled receptors as therapeutic targets. None of the compounds under study herein are patented by Servier; capadenoson and neladenoson are compounds published by Bayer and VCP746 is a tool compound previously reported by Monash University.

Copyright (C) 2021 Rueda, Merlin, Chimenti, Feletou, Paysant, White, Christopoulos, Sexton, Summers, Charman, May and Langmead. This is an open-access article distributed under the terms of the Creative Commons Attribution License (CC BY). The use, distribution or reproduction in other forums is permitted, provided the original author(s) and the copyright owner(s) are credited and that the original publication in this journal is cited, in accordance with accepted academic practice. No use, distribution or reproduction is permitted which does not comply with these terms. 